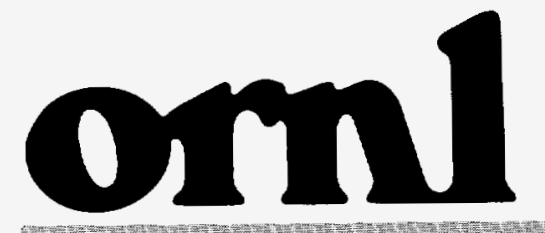

OAK RIDGE

NATIONAL

LABORATORY

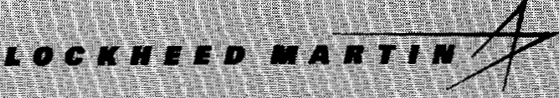

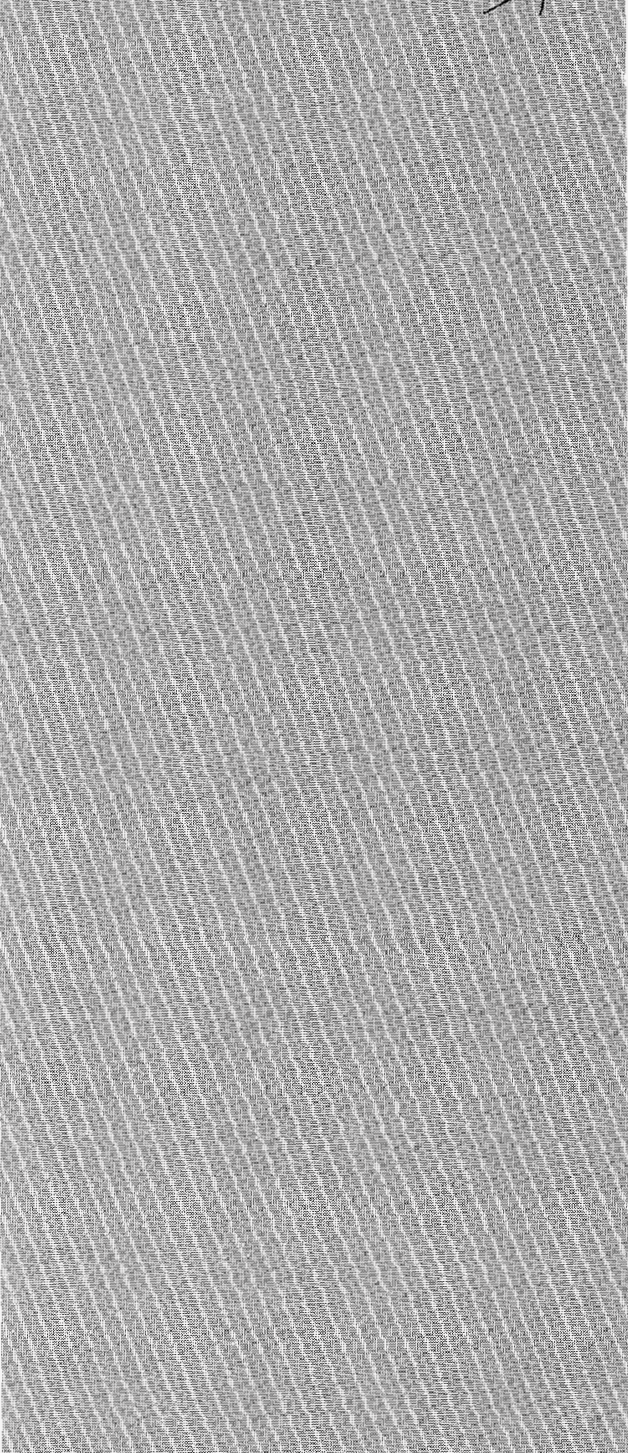

WWWGED ANO OPERMTEO DY

LOCKHEED WARTH EYERGY RESEARCH CORPORA HION FOA THE UNTED STATES

DEPARTUENT OF ENIBAG

\title{
Creating Competitive Markets for Ancillary Services
}

Eric Hirst

Brendan Kirby

\section{MASTER}


This report has been reproduced directly from the best available copy.

Available to DOE and DOE contractors from the Office of Scientific and Technical information, P.O. Box 62, Oak Ridge, TN 37831; prices available from (423) 576-8401, FTS 626-8401.

Available to the public from the National Technical Information Service, U.S. Department of Commerce, 5285 Port Royal Rd., Springfield, VA 22161.

This report was prepared as an account of work sponsored by an agency of the United States Government. Neither the United States Government nor any agency thereot, nor any of their employees, makes any warranty, express or implied, or assumes any legal liability or responsibility for the accuracy, completeness, or usefulness of any information, apparatus, product, or process disclosed, or represents that its use would not infringe privately owned rights. Reference herein to any specific commercial product, process, or service by trade name, trademark, manufacturer, or otherwise, does not necessarily constitute or imply its endorsement, recommendation, or favoring by the United States Government or any agency thereof. The views and opinions of authors expressed herein do not necessarily state or reflect those of the United States Government or any agency thereof. 


\section{DISCLAIMER}

Portions of this document may be illegible electronic image products. Images are produced from the best available original document. 
ORNL/CON-448

ENERGY DIVISION

\title{
CREATING COMPETITIVE MARKETS FOR ANCILLARY SERVICES
}

\author{
ERIC HIRST and BRENDAN KIRBY
}

October 1997

\begin{abstract}
Sponsored by
Office of Utility Technologies

Office of Energy Efficiency and Renewable Energy

U.S. Department of Energy
\end{abstract}

OAK RIDGE NATIONAL LABORATORY

Oak Ridge, Tennessee 37831

managed by

LOCKHEED MARTIN ENERGY RESEARCH CORPORATION

for the

U.S. DEPARTMENT OF ENERGY

under contract No. DE-AC05-96OR22464 



\section{CONTENTS}

Page

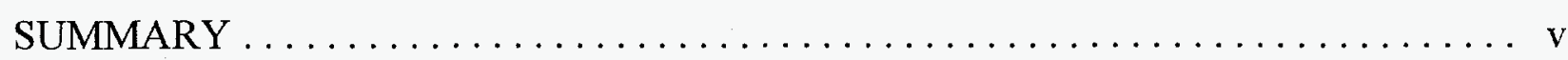

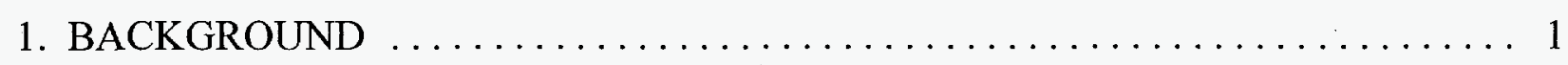

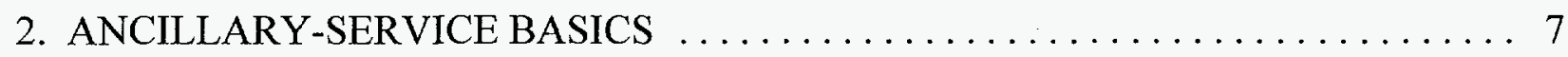

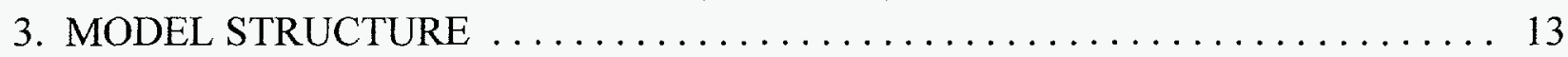

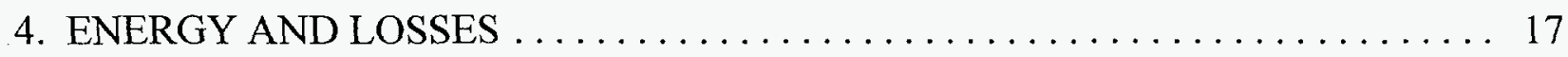

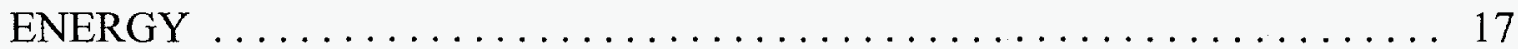

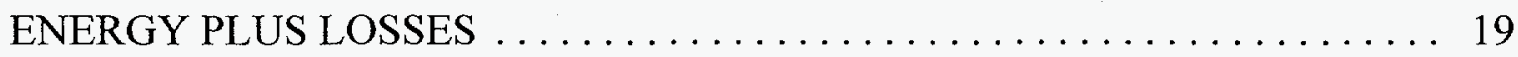

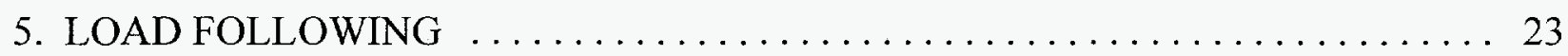

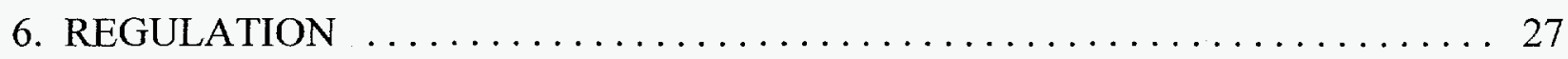

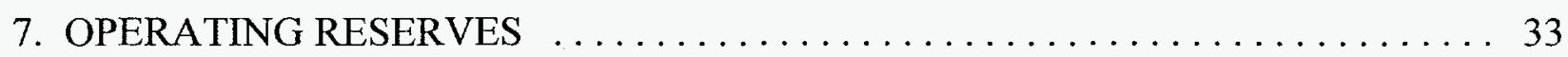

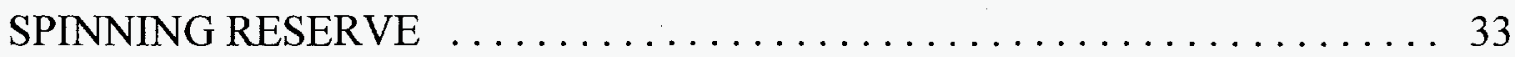

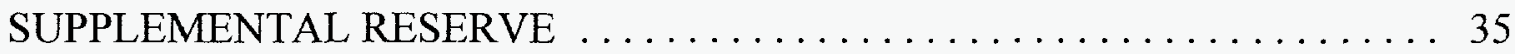

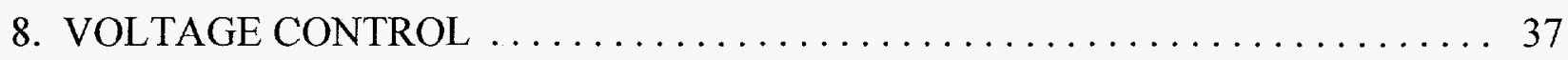

9. ENERGY IMBALANCE AND SYSTEM CONTROL $\ldots \ldots \ldots \ldots \ldots \ldots \ldots$

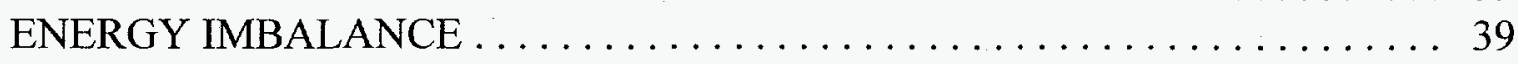

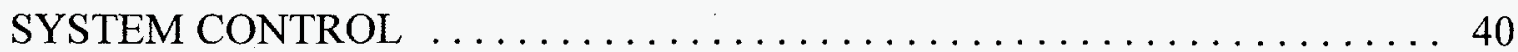

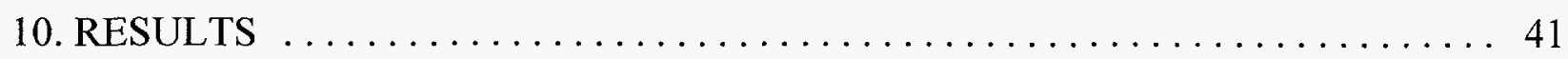

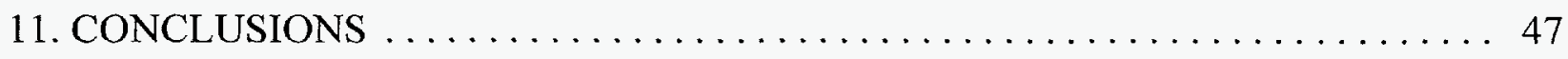

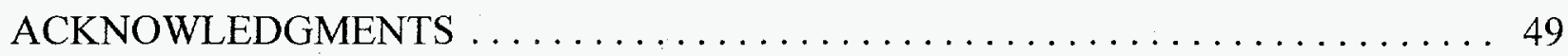

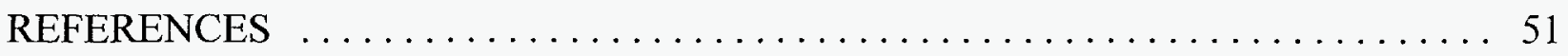





\section{SUMMARY}

Ancillary services are those functions performed by the equipment and people that generate, control, and transmit electricity in support of the basic services of generating capacity, energy supply, and power delivery. The Federal Energy Regulatory Commission (FERC) defined such services as those "necessary to support the transmission of electric power from seller to purchaser given the obligations of control areas and transmitting utilities within those control areas to maintain reliable operations of the interconnected transmission system." This statement recognizes the importance of ancillary services for bulk-power reliability and to support commercial transactions.

FERC's landmark Order 888 included a pro forma tariff with provisions for six key ancillary services. Most of the tariffs filed with FERC to date price these services on the basis of traditional cost-of-service (embedded) costs. Because most of these services are provided by generating units, however, it should be possible to create competitive markets for the provision, acquisition, and pricing of these services. Indeed, the recent proposals to create independent system operators in several regions of the country call for just such markets. Unfortunately, these proposals, with the possible exception of the one from California, lack details on how these markets would be structured and operated.

This report describes the structure of, and results from, a spreadsheet model. The model simulates markets for seven services: losses, regulation, spinning reserve, supplemental reserve, load following, energy imbalance, and voltage support. For completeness, the model also calculates costs for system control, although this service will continue to be provided solely by the system operator under cost-based prices.

Developing this computer model demonstrated, over and over, the likely complexity of markets for energy and ancillary services. This complexity arises because these markets are highly interdependent. For example, the cost of regulation (the frequent change in generator outputs to track the minute-to-minute fluctuations in system load) depends strongly on which units are already being dispatched to provide energy and losses, their variable costs, and their operating levels relative to their maximum and minimum loading points. In a similar fashion, the cost of spinning reserve depends on the market for regulation (as well as for energy and losses).

Because these markets are interactive, the costs (and therefore the prices) of these services will vary considerably as functions of system load and the current spot price of energy. The price of ancillary services in aggregate is highly correlated with the price of energy. 
These results suggest that the embedded-cost prices used by most utilities in their Order-888 tariffs bear little relationship to the costs and prices that would actually occur in competitive markets. Specifically, the capital costs that figure so prominently in the tariff prices are largely irrelevant in short-term competitive markets. And opportunity costs, ignored in costof-service analysis, dominate the prices of some ancillary services at some times.

Competitive markets for energy and ancillary services will likely develop in different ways throughout the country. Market structures can differ according to their timing (sequential or simultaneous provision of energy and ancillary services), the amount of information individual suppliers provide to the system operator, and the role of the system operator in facilitating or controlling these markets.

We developed a base-case utility for use with our model. This base case includes 25 generating units with a total capacity of $10,000 \mathrm{MW}$, customer demands that peak at $8300 \mathrm{MW}$, and many assumptions about the details of providing and costing ancillary services. For this set of assumptions, ancillary-service costs amount to about $10 \%$ of the direct energy costs that customers experience. Losses are the most expensive service, accounting for about a third of the total ancillary-services bill (Fig. S-1).

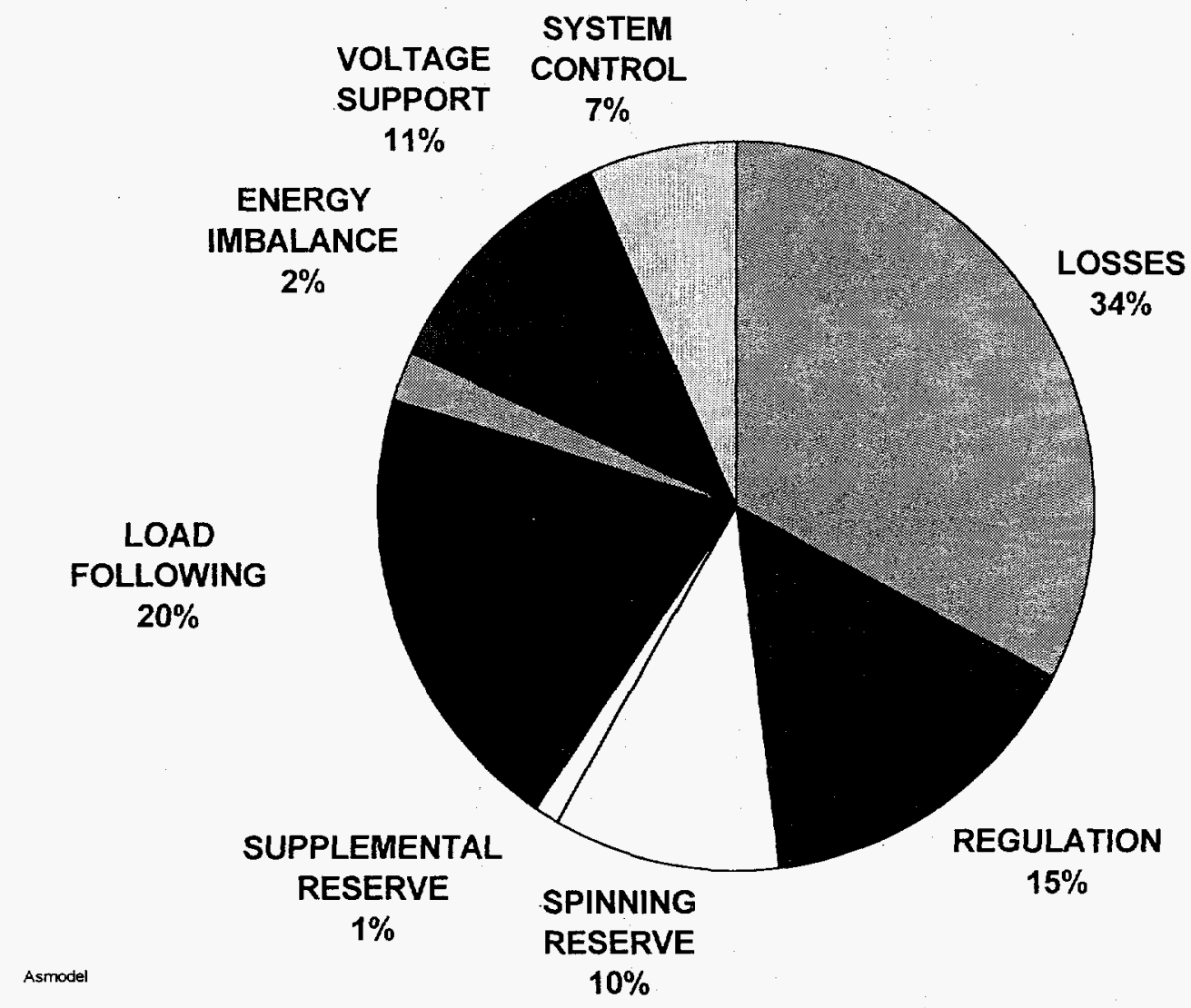

Fig. S-1. The allocation of ancillary-service costs for the base-case system developed here. In aggregate, these services cost the equivalent of $\$ 2.3 /$ MWh during the course of a year. 


\section{BACKGROUND}

Until a few years ago, hardly anyone in the electricity industry knew about ancillary services. Now we are in the process of creating competitive markets for functions that, in the past, were rarely considered. These operations support the basic services of generating capacity, energy production, and power delivery. They are required to maintain system reliability and to effect commercial transactions across the transmission grid. These services currently cost U.S. electricity consumers about $\$ 12$ billion a year, roughly $\$ 4 / M W h$ (Kirby and Hirst 1996).

The Federal Energy Regulatory Commission's (FERC's) decision to functionally unbundle generation from transmission exposed the array of bulk-power functions called ancillary services. Stimulated by FERC's development of an open-access transmission regime, several entities, including FERC (1996 and 1997), Oak Ridge National Laboratory (Hirst and Kirby 1996a), and the Interconnected Operations Services Working Group (1997), developed comprehensive lists and definitions of ancillary services. Although the three sets share many similarities in nomenclature, coverage, and definition, they also exhibit differences. None of these studies detailed the metrics, costs, and appropriate pricing methods for these services.

More recently, several entities have filed proposals with FERC to create independent system operators, all of which describe ancillary services. These filings are from the New England Power Pool (1996), the New York Power Pool (1997), the PJM Interconnection (Atlantic City Electric et al. 1997), and California (Pacific Gas and Electric et al. 1997). These filings call for the creation of competitive markets in which the independent system operator will acquire certain ancillary services on behalf of the customers within that system.

This report discusses how such markets might be defined and operated. It also describes and presents results from a computer model that simulates the operation of combined markets for energy and ancillary services. We use the model to illustrate how such markets might operate and what the results (in terms of prices and generator earnings) might be.

Many researchers have written about optimal pricing for power, transmission, and even ancillary services in competitive bulk-power markets (Hogan 1993; Ilic et al. 1996; Kirsch 1996; and Kirsch and Singh 1995). In general, these publications focus on theory and offer few quantitative estimates of what the prices might actually be. For example, Baughman, Siddiqi, and Zarnikau (1997) developed a "mathematical formulation of a model for real-time pricing of electricity that includes selected ancillary services," but their paper offers no numerical estimates of what these prices might be and how they might vary over time and location. Indeed, they note that the "software, hardware, manpower, and computational requirements [to implement their method] are formidable." 
Because such markets did not exist in the past-indeed there was no call to even consider such commercial services in the past-creating viable markets for ancillary services will not be easy. Some of the difficulty stems from the lack of experience with such markets. More stems from the complexity of these services and the relationships among these services and between them and the provision of the basic energy and capacity services. Although not explored in this report, we believe that alternative approaches to the creation and operation of ancillary-service markets can yield differences in producer revenues and profits and in customer prices. Such differences might also affect bulk-power reliability (Hirst 1997).

Our results are especially interesting because they show the importance of opportunity costs (not a consideration in regulated markets), the irrelevance of capital costs (very important in regulated markets) in the short term," the volatility in prices, and the sharing of risks and information between generator suppliers and the system operator. Our model yields prices that are substantially different in structure from those filed by most utilities in response to FERC's Order-888 requirement for pro forma tariffs.

Consider regulation (the use of generating units to follow minute-to-minute fluctuations in system load) as an example of the differences that might occur between competitive and regulated markets. Regulation is the use of generating units that are online and equipped with governors and automatic generation control. These generators are used to track the moment-tomoment fluctuations in customer loads and the unintended fluctuations of other generators. In so doing, the regulation service helps to maintain frequency within the interconnection at its $60-\mathrm{Hz}$ reference value, minimizes differences between actual and scheduled power flows between control areas, and matches generation to load within the control area.

The tariffs filed by most utilities in compliance with Order 888 fail to comport with the underlying physics of regulation in two respects." First, the tariffs filed with FERC by most utilities price regulation on the basis of a customer's average hourly load (e.g., in $\$ / M W h$ ). But the regulating burden imposed by customers on the system has nothing to do with average load. That burden is a function of the volatility of the customer's load (e.g., as measured by its standard deviation) and the correlation between a customer's load volatility and that of the system as a whole.

*In the long term, capital costs affect market entry and exit. If short-term markets do not provide enough revenues above variable costs to cover fixed costs (both operations and maintenance as well as capital costs), generator owners will retire units and decline to build new generating capacity. The model discussed here focuses on short-term markets.

"In fairness, utilities had little time to prepare innovative rate proposals for these FERC tariffs. Also, utilities may have preferred to file traditional, embedded-cost-based rates to avoid litigation and because they lack sufficient data to support marginal-cost-based rates. 


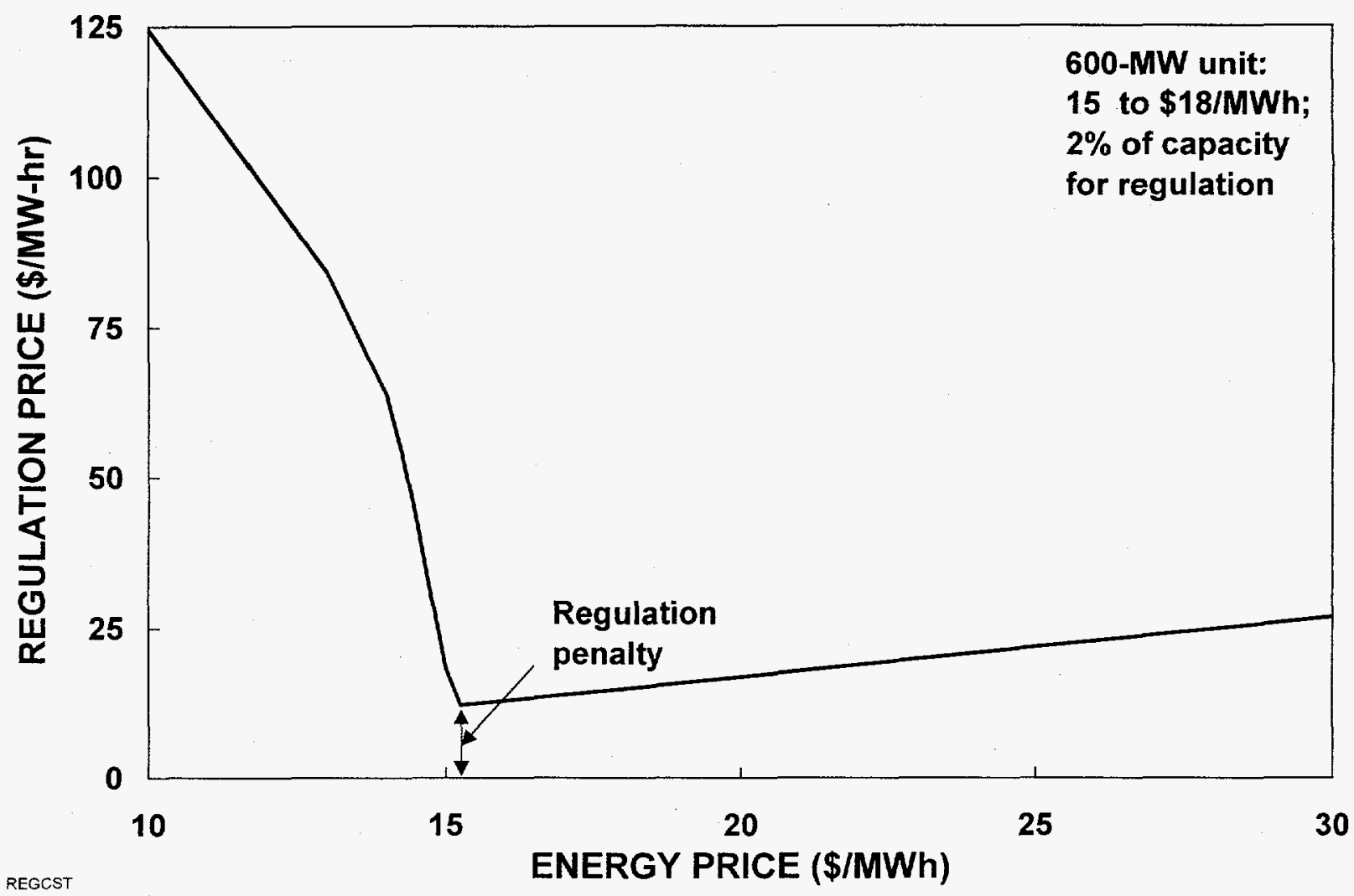

Fig. 1. The minimum price for regulation that a hypothetical 600-MW generator would require in a competitive market as a function of the spot price of energy.

Second, most tariffs charge a uniform price for regulation. In competitive markets, however, the price of regulation will almost surely vary from hour to hour, based primarily on the current spot price for energy. Figure 1 shows the minimum price that a particular $600-\mathrm{MW}$ generator would need to receive to make it worthwhile for it to provide regulation. At values of spot price below the unit's variable cost, the revenue generated by regulation must compensate the generator for the economic losses it would otherwise experience in the energy market (e.g., producing at a variable cost of $\$ 15 / \mathrm{MWh}$ and selling into a $\$ 12 / \mathrm{MWh}$ market requires that the $\$ 3 / \mathrm{MWh}$ loss be charged to regulation). ${ }^{*}$ At high values for market price, the generator foregoes profits in the energy market when providing regulation. For example, if the generator provides $12 \mathrm{MW}$ of regulation at a time when the spot market price is $\$ 20 / \mathrm{MWh}$, it foregoes the opportunity to earn $\$ 60$ /hour $[(\$ 20-\$ 15) \times 12 \mathrm{MW}]$ in the energy market. Finally, the generator must be compensated for the energy-efficiency losses and incremental operating costs, combined here into a regulation penalty that is assumed to equal $\$ 12$ /hour for each MW of regulation provided.

*This $\$ 3 / \mathrm{MWh}$ charge applies to the unit's minimum load (e.g., $150 \mathrm{MW}$ ) plus the regulation footroom (e.g., $12 \mathrm{MW}$ ), for a total of $\$ 486 /$ hour in this example. 
One can envision alternative structures and rules for the operation of competitive energy and ancillary-services markets. The system modeled here involves sequential market computations, in which the results of one market (e.g., energy plus losses) represent the starting point for the next market (e.g., regulation). In this kind of market structure, the system operator plays a very important role in balancing supply, demand, and prices in each market. And the prices of energy and some ancillary services can vary from market to market because of these redispatch actions.

An alternative approach could involve simultaneous determination of the supply, demand, and prices for each market. In such a structure, the system operator would not need to redispatch (i.e., adjust) generating units from an already closed market to allow for reasonable operation of the existing market (e.g., changing the energy output of individual generators to allow sufficient headroom and footroom for provision of regulation). With simultaneous determination, only one set of energy and ancillary-service prices exist.

In either the sequential or simultaneous approaches, market structures could differ in the amount of control given to the system operator. At one end of the spectrum, the system operator could collect detailed information on the costs and characteristics of each generating unit (including startup and no-load costs, minimum startup and shutdown times, and the incremental heat rates for several points between minimum and maximum unit output). The system operator would then use this information in a unit-commitment model to determine the optimal allocation of generation resources across all the energy and ancillary services. This approach offers the promise of lowest system cost for energy plus ancillary services. However, as one study showed, "alternative near-optimal schedules which are equally good from the perspective of social cost have significantly diverse implications on the profitability of individual resources" (Oren, Svoboda, and Johnson 1996). The owners of individual generators may not want to be subject to the whims of an arcane unit-commitment model and might prefer to make such decisions themselves.

At the other end of the spectrum, each supplier could be responsible for its own decisions on what and how to bid into the various energy and ancillary-service markets. In this approach, bidders bear all the risks of poor decisions and might be faced with suboptimal or even impossible operations of their units (e.g., a shift from full output of the unit in one hour to zero output the following hour and back up to full output for the third hour, requiring a ramp rate beyond the unit's capabilities). The California approach proposes to overcome this problem by having multiple rounds of bids in the day-ahead markets. Thus, bidders can examine the results from one round and then modify their bids in subsequent rounds to ensure both feasible operation of their units and profitability. Over time, suppliers should learn how the markets for various services operate and how best to bid into the various markets. (This process of learning with experience applies to all market structures. However, suppliers may have more opportunity to adjust their bids and influence their earnings in some structures than in others.) 
As the foregoing discussion suggests, competitive markets for energy and ancillary services can, and are likely to, develop in different ways in different parts of the country. Only time and experience will show which market structures discourage gaming and yield efficient outcomes. The challenge is to determine which decisions can best be made by regulators or system operators and which ones are best left to market participants. Thus, the model structure and results presented here should be viewed as illustrative, not definitive. Our purpose is not to specify the algorithm that should be used. Rather, it is to develop insights concerning the operation of, interactions among, and prices that result from competitive bulk-power markets.

This report is organized as follows. Chapter 2 presents brief definitions for the key ancillary services identified by the Interconnected Operations Services Working Group. Chapter 3 explains the overall structure of our model. Chapters 4 through 9 present the model structure and results for energy, energy plus losses, load following, regulation, spinning reserve, supplemental reserve, energy imbalance, voltage control, and system control (eight services in all). Thus, only 4 of the 12 services discussed by the Interconnected Operations Services Working Group are not analyzed here: dynamic scheduling, backup supply, system-black-start capability, and network stability. All four services involve time scales longer than an hour. Backup supply is not called into service until after the operating reserves "expire," usually an hour or so. The other three services, none of which is likely to be bought and sold in competitive markets, operate for months and years, not the hourly level that is the focus of this report. Chapter 10 presents summary results from the use of this model. And Chapter 11 presents our key findings. 



\section{ANCILLARY-SERVICE BASICS}

Table 1 shows the FERC and Interconnected Operations Services Working Group names and definitions for 12 ancillary services. The seven services that Hirst and Kirby defined cover the six that FERC required transmission providers to offer plus losses.

FERC specified two services that transmission customers are required to obtain from the transmission provider," system control and voltage control. FERC determined that these services can only be provided by the local control area. FERC specified four additional services that the transmission provider must offer to transmission customers that serve load within the transmission provider's control area. For these four services, however, FERC allows transmission customers to obtain the service in any one of three ways: from the transmission provider, from another source, or by self-provision.

FERC also discussed other ancillary services, including, real-power-loss replacement, dynamic scheduling, backup supply, and black-start capability. FERC determined that these services either could be provided competitively, were very inexpensive, or were highly location specific and therefore did not require transmission providers to unbundle and offer them as separate services.

The Interconnected Operations Services Working Group identified 12 services, including two that FERC did not discuss at all: load following [also emphasized by Hirst and Kirby (1996b)] and network-stability service. Other entities identified additional services. To illustrate, the New York Power Pool (1997) includes stormwatch as an ancillary service. This service entails the redispatch of generating units to provide additional transmission reserves in anticipation of potential weather-related contingencies. The Electric Reliability Council of Texas includes responsive reserve, the portion of spinning reserve that responds to outages "within the first few minutes." It also divides energy imbalance into two services, generationschedule and load-schedule imbalances.

*Today's transmission provider usually owns and operates generating units and operates a control area and is, most often, a vertically integrated utility. In a technical sense, the mere ownership of transmission facilities is not enough to provide and manage ancillary services; only control-area operators have sufficient real-time information to perform these functions. In the future, we believe that such functions will increasingly be assigned to independent system operators. Independent means an entity that has no commercial interests in electricity markets. 
Table 1. Key ancillary services and their definitions

\begin{tabular}{|c|c|c|}
\hline Service & Description & Time scale \\
\hline \multicolumn{3}{|c|}{$\begin{array}{l}\text { Services FERC requires transmission providers to offer and customers to take from } \\
\text { the transmission provider }\end{array}$} \\
\hline System control & $\begin{array}{l}\text { The control-area operator functions that schedule generation and } \\
\text { transactions before the fact and that control some generation in real-time } \\
\text { to maintain generation/load balance; Interconnected Operations Services } \\
\text { Working Group definition more restricted, with a focus on reliability, not } \\
\text { commercial, activities, including generation/load balance, transmission } \\
\text { security, and emergency preparedness }\end{array}$ & $\begin{array}{l}\text { Seconds to } \\
\text { hours }\end{array}$ \\
\hline $\begin{array}{l}\text { Reactive supply } \\
\text { and voltage } \\
\text { control from } \\
\text { generation }\end{array}$ & $\begin{array}{l}\text { The injection or absorption of reactive power from generators to maintain } \\
\text { transmission-system voltages within required ranges }\end{array}$ & Seconds \\
\hline \multicolumn{3}{|c|}{$\begin{array}{l}\text { Services FERC requires transmission providers to offer but which customers can take from } \\
\text { the transmission provider, third parties, or self-provide }\end{array}$} \\
\hline Regulation & $\begin{array}{l}\text { The use of generation equipped with governors and automatic-generation } \\
\text { control to maintain minute-to-minute generation/load balance within the } \\
\text { control area to meet NERC control-performance standards }\end{array}$ & $\sim 1$ minute \\
\hline $\begin{array}{l}\text { Operating reserve } \\
\text { - spinning }\end{array}$ & $\begin{array}{l}\text { The provision of generating capacity (usually with governors and } \\
\text { automatic-generation control) that is synchronized to the grid and is } \\
\text { unloaded that can respond immediately to correct for generation/load } \\
\text { imbalances caused by generation and transmission outages and that is } \\
\text { fully available within } 10 \text { minutes }\end{array}$ & $\begin{array}{l}\text { Seconds to } \\
<10 \text { minutes }\end{array}$ \\
\hline $\begin{array}{l}\text { Operating reserve } \\
\text { - supplemental }\end{array}$ & $\begin{array}{l}\text { The provision of generating capacity and curtailable load used to correct } \\
\text { for generation/load imbalances caused by generation and transmission } \\
\text { outages and that is fully available within } 10 \text { minutes }{ }^{\text {a }}\end{array}$ & $<10$ minutes \\
\hline \multirow[t]{2}{*}{ Energy imbalance } & $\begin{array}{l}\text { The use of generation to correct for hourly mismatches between actual } \\
\text { and scheduled transactions between suppliers and their customers }\end{array}$ & Hourly \\
\hline & Services FERC does not require transmission providers to offer & \\
\hline Load following & $\begin{array}{l}\text { The use of generation to meet the hour-to-hour and daily variations in } \\
\text { system load }\end{array}$ & Hours \\
\hline Backup supply & $\begin{array}{l}\text { Generating capacity that can be made fully available within one hour; } \\
\text { used to back up operating reserves and for commercial purposes }\end{array}$ & $\begin{array}{l}30 \text { to } 60 \\
\text { minutes }\end{array}$ \\
\hline $\begin{array}{l}\text { Real-power-loss } \\
\text { replacement }\end{array}$ & $\begin{array}{l}\text { The use of generation to compensate for the transmission-system losses } \\
\text { from generators to loads }\end{array}$ & Hourly \\
\hline $\begin{array}{l}\text { Dynamic } \\
\text { scheduling }\end{array}$ & $\begin{array}{l}\text { Real-time metering, telemetering, and computer software and hardware to } \\
\text { electronically transfer some or all of a generator's output or a customer's } \\
\text { load from one control area to another }\end{array}$ & Seconds \\
\hline $\begin{array}{l}\text { System-black-start } \\
\text { capability }\end{array}$ & $\begin{array}{l}\text { The ability of a generating unit to go from a shutdown condition to an } \\
\text { operating condition without assistance from the electrical grid and to then } \\
\text { energize the grid to help other units start after a blackout occurs }\end{array}$ & $\begin{array}{l}\text { When outages } \\
\text { occur }\end{array}$ \\
\hline $\begin{array}{l}\text { Network-stability } \\
\text { services }\end{array}$ & $\begin{array}{l}\text { Maintenance and use of special equipment (e.g., power-system stabilizers } \\
\text { and dynamic-braking resistors) to maintain a secure transmission system }\end{array}$ & Cycles \\
\hline
\end{tabular}

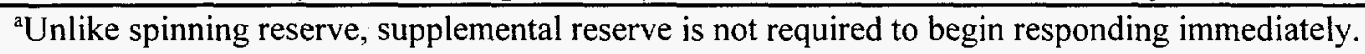


Each service is briefly defined below. Readers interested in additional detail are urged to read the documentation provided by FERC, the Interconnected Operations Services Working Group, and Hirst and Kirby.

System control is the control-area operator functions that (1) schedule generating units, transmission resources, and transactions before the fact and (2) monitor and control transmission resources and some generating units in real time to maintain reliability. While individual market participants can handle many of the scheduling and dispatch functions, including most of the economic risk, the local control-area operator still has a major role for reliability reasons. This service could also include after-the-fact accounting and billing.

- Voltage control is the use of generating and transmission-system equipment to inject or absorb reactive power to maintain voltages on the transmission system within required ranges. FERC decided that the costs of voltage control provided by transmission equipment (e.g., through capacitors, tap-changing transformers, condensers, reactors, and static var compensators) should be incorporated into the basic transmission tariffs, and not charged for separately. FERC decided that voltage control provided by generators should be a separate service. (In general, generators can change their production and absorption of reactive power much more rapidly than can transmissionrelated voltage-control equipment.) Because reactive power losses are much greater than real power losses, voltage-control equipment must generally be dispersed throughout the system and located close to where the voltage support is needed.

- Regulation is the use of online generating units that are equipped with governors and automatic generation control and that can change output quickly (MW/minute) to track the moment-to-moment fluctuations in customer loads and unintended fluctuations in generation. In so doing, regulation (along with spinning reserve) helps to maintain interconnection frequency, minimize differences between actual and scheduled power flows between control areas, and match generation to load within the control area. This service can be provided by any appropriately equipped generator that is connected to the grid and electrically close enough to the local control area that physical and economic transmission limitations do not prevent the importation of this power.

- Load following is the use of online generation equipment to track the interhour changes in customer loads. Unlike the minute-to-minute fluctuations, which are generally uncorrelated among customers, the hourly and diurnal changes in customer loads are generally correlated with each other. As with regulation, this service can be provided by any generator that is connected to the grid and electrically close enough to the local control area that transmission limitations do not prevent the importation of this power.

Spinning reserve is the use of generating equipment that is online and synchronized to the grid that can begin to increase output immediately in response to changes in 
interconnection frequency and that can be fully available within 10 minutes to correct for generation/load imbalances caused by generation or transmission outages. ${ }^{*}$ In principle, loads under the control of the system operator could help provide this service. This service can be provided by any generator that is connected to the grid and electrically close enough to the local control area that transmission limitations do not prevent the importation of this power.

- Supplemental reserve is the use of generating equipment and interruptible load that can be fully available within 10 minutes to correct for generation/load imbalances caused by generation or transmission outages." Supplemental reserve differs from spinning reserve only in that supplemental reserve need not begin responding to an outage immediately. This service can be provided by any generator that is electrically close enough to the local control area that transmission limitations do not prevent the importation of this power. This service may also include the provision of additional generating capacity that must be fully available within 30 or 60 minutes (the exact time depends on the rules of the regional reliability council) and can then be maintained until commercial arrangements can be made (e.g., for two hours) to "back up" the normal supply for the load.

- Backup supply is a service that customers would purchase to protect against forced outages at the generating units that provide their energy or against loss of transmission between their normal supply and their load. This service is not called into operation until after operating reserves are returned to normal service (30 to 120 minutes). Backup supply can be provided by any generator that is electrically close enough to the local control area that transmission limitations do not prevent the importation of this power. Unlike spinning and supplemental operating reserves, which are system services required for reliability, backup supply is a commercial service that supports individual transactions. A customer that did not purchase backup supply would be required to disconnect its load from the grid when its power supply failed or buy on the spot market.

- Energy imbalance is the use of generating equipment and fuel to match any differences between actual and scheduled transactions between suppliers and their customers.

*The generating units that provide spinning reserve are often the same units that provide regulation. Almost all generators that supply spinning reserve are equipped with governors and automatic generation control.

${ }^{\#}$ Different reliability regions define different time periods for operating reserves and backup supply. For example, the California independent system operator proposal requires that operating reserves must be capable of being maintained for two hours, and that what they call replacement reserve must be fully available within 60 minutes and can then be maintained for two hours. The NEPOOL (1996) proposal calls for a 30-minute operating reserve, rather than California's 60-minute reserve. The FERC definition of supplemental reserve is ambiguous. It could mean (1) fast reserves required to respond to a contingency or (2) slower reserves that are used to back up operating reserves and protect against a second contingency. 
Energy imbalance is usually measured at hourly increments. "FERC's definition of this service includes only load imbalances because it believes that generators can and will meet their schedules accurately. The Interconnected Operations Services Working Group, however, includes both load and generator imbalances in its definition. This service can be provided by any generator that is connected to the grid and electrically close enough to the local control area that transmission limitations do not prevent the importation of this power.

- Real-power-loss replacement is the use of generating equipment and fuel to compensate for the transmission-system losses associated with power flows from generators to customers. This is clearly a service that can be provided by a third party because it is so closely related to the basic energy and capacity services provided by generators. (Some people consider losses a part of the basic energy service, not a separate function.)

- Dynamic scheduling is the electronic transfer from one control area to another of the time-varying electricity consumption of a load or the time-varying electricity production from a generator. Dynamic scheduling involves metering the power consumption of the load or production of the generator at the same frequency as the other parameters critical to control of the power system, usually every two to eight seconds. The metered signal is sent to the control centers of both the physical-host control area and the electronichost control area (the control area assuming responsibility for the load or generation). The physical host uses the signal to remove the load or generation from its responsibility, while the electronic host uses the signal to assume control responsibility. This service will help enable the creation of competitive markets for ancillary services by increasing choices for suppliers and customers. This service requires the full involvement of, and coordination between, the physical-host and electronic-host control areas.

System-black-start capability is the ability of generating units to go from a shutdown condition to an operating condition without support from the electrical system. This capability, coordinated by the system operator, is essential during large-scale blackouts and islanding because such units can start themselves and then produce power that can

"Three elements are implicit in FERC's definition of energy imbalance (Hirst and Kirby 1996a). The first includes only the discrepancies within a defined deadband measured over a defined time interval (e.g., $\pm 1.5 \%$ for 60 minutes). Backup supply, the second element, would be contractually arranged beforehand between the customer and a supplier (not necessarily the local control area). Unauthorized use, the third element, would result in penalty charges imposed by the local control area if (1) the customer's load fell outside the deadband and (2) the customer had not arranged for standby service or the standby service failed to perform. Because unauthorized use is not a service, its charge would not be based on costs. Rather, its price would be designed to encourage customers to obtain standby service and to discourage them from leaning on the local control area. Alternatively, energy imbalance can be settled at the hourly spot price, eliminating the need for deadbands, penalties, and intricate accounting. This market approach is the one adopted in our model (Chapter 9). 
be used to energize the grid and provide power to start other generating units. This service is, like voltage control, somewhat location dependent, which may limit the ability of third parties to provide the service.

- Network stability is the use of special equipment at a power plant (such as power-system stabilizers or dynamic braking resistors) or on the transmission system (such as DC lines, FACTS devices, ${ }^{*}$ or energy storage devices) to help maintain transmission-system stability and reliability. This service is, like voltage control and system-black-start capability, somewhat location dependent.

*FACTS refers to flexible AC transmission systems, the use of high-speed solid-state technologies to control transmission equipment, thereby improving reliability and increasing capacity. 


\section{MODEL STRUCTURE}

Our model is an Excel workbook containing several spreadsheets. The model defines the characteristics of the bulk-power system for a particular hour, including the amounts of each ancillary service required. The model then purchases these services from individual generators to meet system requirements for that hour.

As with all mathematical representations of complex physical and market phenomena, our model contains many limitations and simplifying assumptions. Perhaps the most important caution is the possibility that the markets for ancillary services will operate in ways different from those represented in the model. More bluntly, the real-world markets that develop in different regions may not conform to the structure, logic, and simplifications of this model. The model's key assumptions include:

- No generators are able to exercise market power (e.g., each generator is owned and operated by a separate entity). Each generator independently offers bids to the system operator based on its actual costs.

The transmission system has no congested interfaces. Further, generation and load are uniformly distributed throughout the grid, which means that real and reactive losses are the same throughout the transmission system (i.e., they vary with system load but not with location).

- As in the California proposal, each market is treated individually and sequentially (not iteratively). The sequence of treatment is from energy to energy plus losses, regulation, spinning reserve, and supplemental reserve." Once a market is closed, the system operator, in essence, guarantees each generator a certain level of earnings for provision of that service. The system operator can redispatch a unit (e.g., reduce the output at a unit because another unit was turned on to provide regulation), but it cannot reduce a unit's earnings."

"To keep our model simple, our analyses of load following, voltage support, and energy imbalance do not involve redispatch of individual generating units. Therefore, these services can be analyzed in any order after the close of the energy-plus-losses market.

"Alternative market structures are possible. For example, one can envision a market in which bidders supply detailed information to the system operator (assumed here to be the market maker). The system operator then calculates the optimal (e.g., least-cost or least-price) mix of resources to meet the combined 
- Because the model treats each hour individually, it cannot handle unit-commitment issues related to startup and shutdown times. Our treatment of must-run conditions and the load-following service are crude approximations because of this temporal limitation in the model.

- All the generators providing a specific service are paid the market price for that service rather than being paid on the basis of their costs (San Diego Gas \& Electric 1996). The market price is set by the most expensive unit that is selected to provide the service.

- The present analysis ignores the role that customers (i.e., loads) can play in providing certain ancillary services, such as operating reserves, to the system.

One set of inputs to the model specifies the annual load-duration curve for the system being served. The model then balances the system for energy and ancillary services for a sample of hours along the load-duration curve ranging from the minimum load to the maximum load. This feature allows the model to calculate annual average costs, profits, and prices for each ancillary service and generator in addition to the hourly details. [Profits are calculated relative to variable (fuel plus operations and maintenance) costs only; our model considers neither fixed operations and maintenance costs nor capital costs.]

The model's inputs include several user-specified factors that determine the amounts and the sources of supply for each ancillary service. These inputs, discussed in greater detail in the following chapters, specify the amounts of real-power and reactive-power losses, system energy-imbalance and load-following requirements, regulation and operating-reserve requirements and the number of units across which these requirements must be spread, the startup costs for generators $(\$ / M W)$, and the number of generators that are treated as must-run units.

Although we like to think of generators as simple devices that produce electricity at a fixed price over a broad range, that is not true. Competitive markets for the outputs from generators need to consider minimum startup and shutdown times, startup and no-load costs, minimum and maximum loading points, plus changes in heat rate (and therefore in variable cost) across the range in output. Figure 2 shows some of the key characteristics of generating units, including the no-load cost (fixed operations and maintenance costs), minimum and

energy and ancillary-service requirements. In this structure, the system operator plays a powerful role in determining outcomes. Another alternative would require the bidders to assume all the risks of incomplete information and poor decisions by requiring them to offer internally consistent bids for each of the services (i.e., to conduct their own unit-commitment analysis). In this structure, the system operator could either accept or reject, but not modify, any of these bids. Such a system could involve one or multiple rounds of bidding; California proposes to use multiple rounds so that suppliers can adjust their offers in response to the information gained in prior rounds of bidding. 


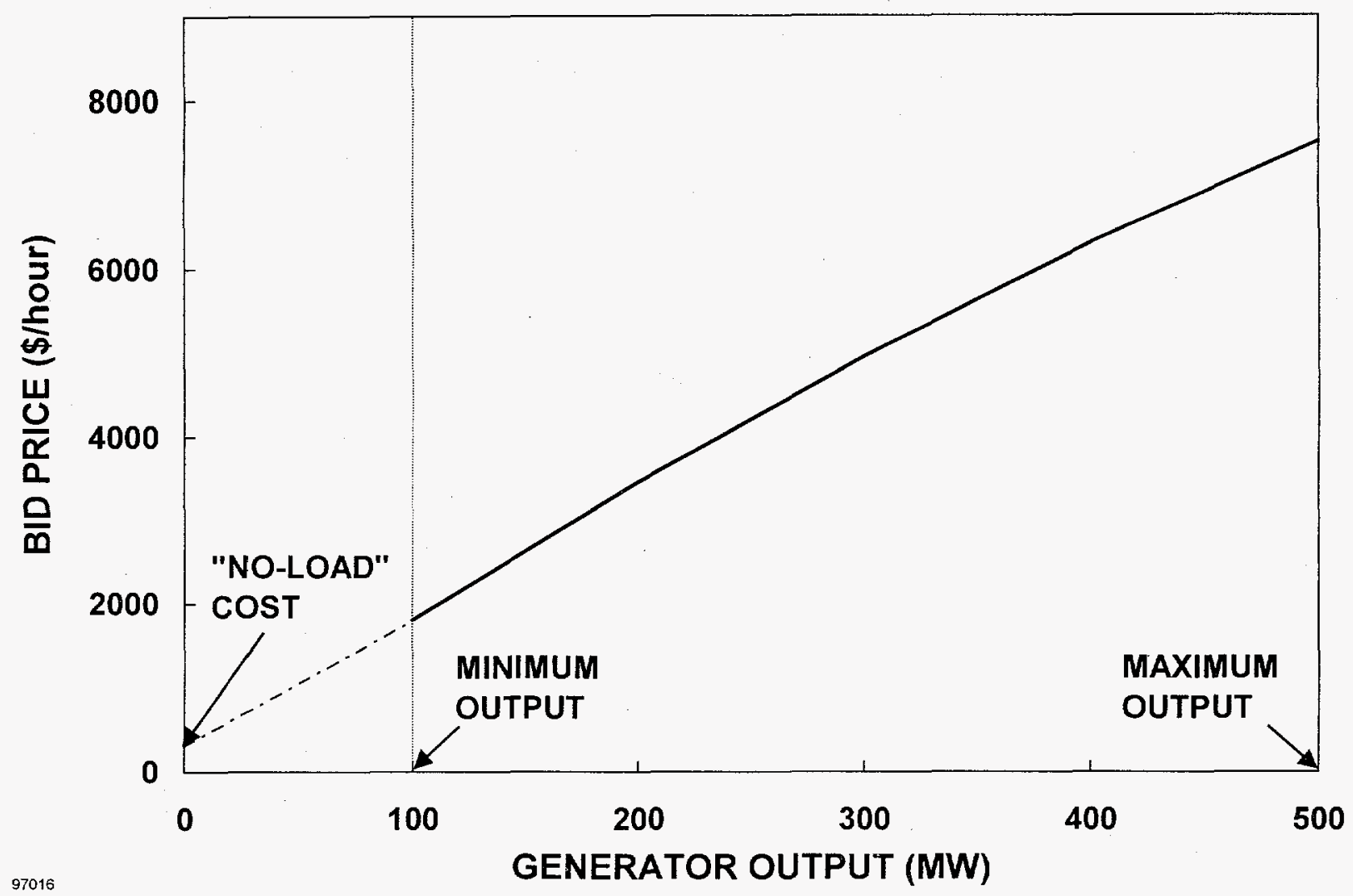

Fig. 2. The key features of a hypothetical generating unit related to real-power capabilities and costs.

maximum output levels, and the running cost of the unit for all levels between the minimum and maximum. The heat rate for most steam-fired generators decreases rapidly from its maximum value at the minimum loading point. The heat rate reaches its minimum value at about three fourths of maximum capacity and remains roughly constant thereafter (Wood and Wollenberg 1996). Our model approximates this nonlinear relationship by assuming that variable costs $(\$ / \mathrm{MWh})$ decline linearly from the unit's minimum operating point to its maximum output (i.e., $\$ / \mathrm{MWh}=a+b \times \mathrm{MW}$, where $\mathrm{a}$ and $\mathrm{b}$ are constants).

Our model includes 25 generating units, intended to represent the population of generators within or electrically close to a particular control area. (U.S. generating units range in size from a few MW to more than $1000 \mathrm{MW}$, with an average of $100 \mathrm{MW}$. Thus, a 10,000MW control area might include about 100 units.) Each generator is characterized by the following factors: minimum and maximum operating points (MW), production costs ( $\$ / \mathrm{MWh}$ ) at these two points with an assumed linear relationship over the unit's operating range, a binary flag that indicates whether the unit is in a must-run condition or not, the maximum ramp rates when the unit is operating and when it is not (MW/10-minutes), the unit's regulation penalty ( $\$ / M W-r e g u l a t i o n)$, the unit's cost of providing supplemental reserve ( $\$ / M W)$, and the unit's unrestricted power-factor capability. 
The base case discussed below is for a 10,100-MW system. The full-output running costs of the 25 generating units range from $\$ 8$ to $\$ 50 / \mathrm{MWh}$. The operating cost at minimum output is assumed to be $15 \%$ higher than at maximum output. The units vary considerably in their maximum ramp rates, ranging from a low of $0.05 \%$ per minute for the large baseload plants to as much as $10 \%$ per minute for the combustion turbines. The units all have design power factors between 0.85 and 0.90 .

The system load varies from $2800 \mathrm{MW}$ to a peak of $8300 \mathrm{MW}$, with an annual load factor of $59 \%$. System real-power losses average 3\% during the course of the year. The amount of regulation required (with a maximum 5-minute response time) is set at $1.2 \%$ of hourly demand, spread across at least three units. The requirements for spinning and supplemental reserves (with maximum 10-minute response times) is set at $3 \%$ of hourly demand, spread across at least four units, for each reserve service. The load-following requirement is set at $5 \%$ of the average annual load, equivalent to $245 \mathrm{MW}$ each hour. The base case assumes that the cheapest four units are must-run for every hour of the year. Finally, startup costs (equivalent to $\$ 40 / \mathrm{MW}$ ) are added to the operating costs for those units that operate with a capacity factor of less than $10 \%$. 


\section{ENERGY AND LOSSES}

Because the focus of this study is on ancillary services, we split energy and losses into its two components. The spot prices for energy plus losses is the price that bulk-power-market participants can expect to face. We discuss a "market" for energy only to isolate the cost of losses, a key ancillary service.

\section{ENERGY}

Given the hourly load, the model first acquires generation from individual units in ascending order of full-output variable cost. Figure 3 shows, for the base-case set of 25 generators, the relationship between system output and marginal cost. The prices at high levels of system demand are adjusted up based on the assumption that the bid prices for units that run only infrequently must reflect their startup costs.

The model then checks to see whether all the units designated as must-run are operating; if not, it adjusts this initial dispatch order to conform to the must-run requirements by loading must-run units at their minimum operating points and lowering output from less expensive units that are already on. At levels of system demand low enough that the must-run constraints apply, spot prices are artificially suppressed.

The model then checks to see whether the units that are dispatched are providing too much or too little energy relative to that required for the hour. If too little energy is being generated, the model dispatches the next most expensive unit. If too much energy is being generated, the model reduces output at the next-to-last unit (the highest cost inframarginal unit). Then the model determines whether the price of energy (which is based on the cost of the most expensive unit running at that time) can be reduced by raising the output at the most expensive unit and lowering output by the same amount at the next-to-last unit. Such changes must, of course, respect the minimum and maximum loading points for both units. Essentially, the model in this step seeks to determine the unit loadings for all those units not fully loaded so that they are all operating at the same marginal cost. Because of our desire to keep this spreadsheet simple, we applied this principle to only the last two units. The market price of energy is then equal to the variable cost of the last (i.e., most expensive) unit online at that unit's operating point. If must-run conditions force units online, the market price is based on the least expensive unit that is not fully loaded.

Must-run requirements artificially suppress the market price of energy by forcing more expensive units online. The difference between the unconstrained and constrained prices 


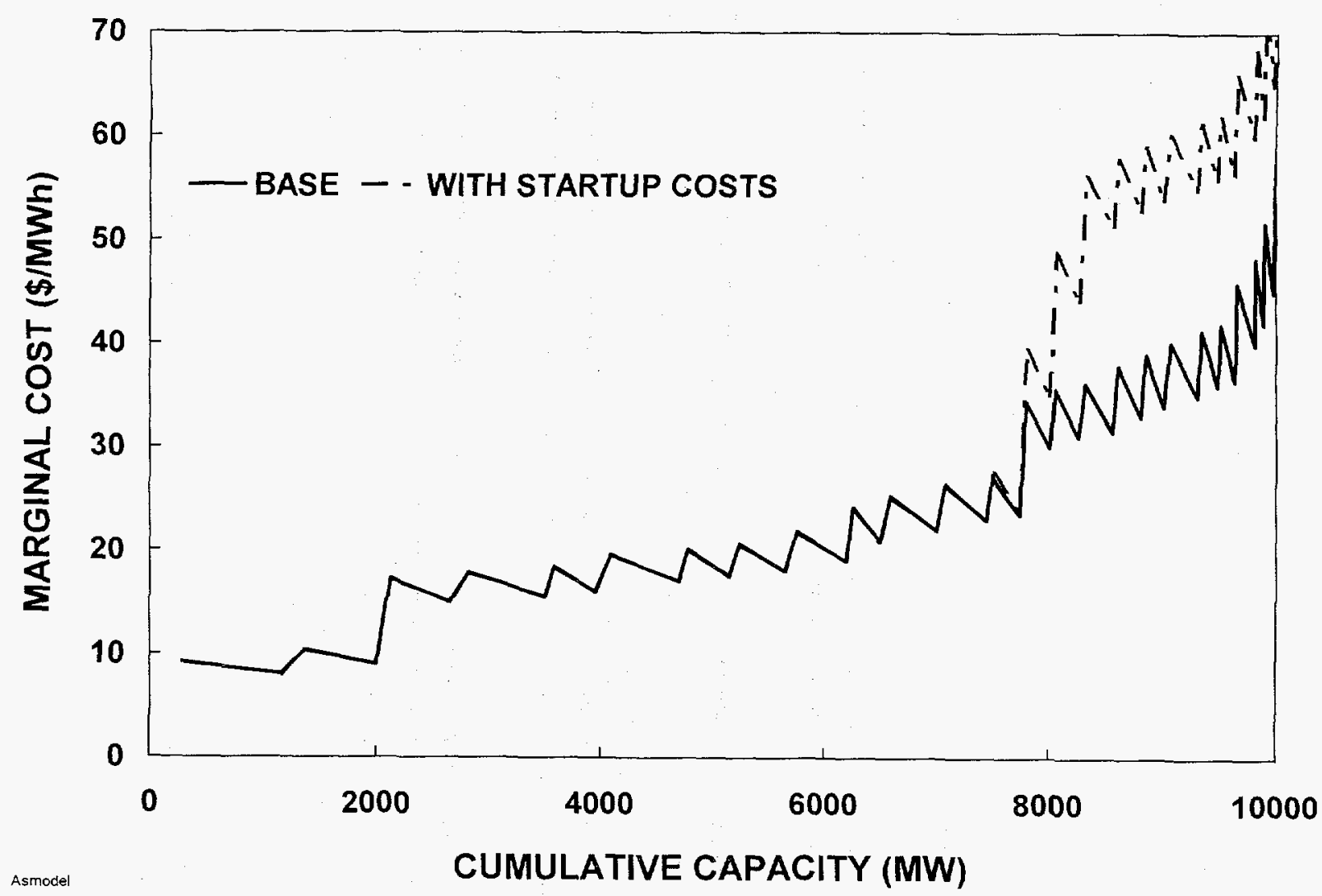

Fig. 3. Marginal costs as a function of cumulative capacity for the 25 generators available to this control area. The upper curve, which includes startup costs for units that operate infrequently, represents the supply curve used in our model.

reflects the cost of inflexibility associated with units that must remain online so that they can meet higher loads at a later time. When such units are forced to operate, the marginal cost is based on an unconstrained inframarginal unit that has lower operating costs than the constrained-on "marginal" unit.

Alternative market structures for energy are possible. Rather than minimize the price paid for energy to suppliers, the system operator could structure the market to minimize the total cost of producing energy, as discussed in Exhibit 1.

Based on this final dispatch for energy, the model calculates the payments to each generator, equal to the spot price of energy for that hour multiplied by the unit's output for that hour. Similarly, the model calculates the operating cost for each unit equal to the product of its variable cost and the unit's output. The unit's earnings are then equal to the difference between revenues (payments) and costs for that hour. 


\section{Exhibit 1. Minimizing the cost or the price of generation}

The unit-specific results and overall costs and prices from generation dispatch could differ depending on the system operator's objective: minimize price or minimize cost. When dispatching units to minimize price, the system operator will increase the output of the pricesetting unit to minimize its variable cost and therefore the system price (in response to the declining-cost nature of the units; note the negative second derivative for the curve shown in Fig. 2). The system operator will make these changes even if this requires backing down a lower-cost unit.

For example, consider a two-unit system consisting of a 100-MW combustion turbine with a cost of $\$ 35 / \mathrm{MWh}$ at minimum load and $\$ 30 / \mathrm{MWh}$ at maximum load and a $1000-\mathrm{MW}$ coal plant with a cost of $\$ 18 / \mathrm{MWh}$ at minimum load and $\$ 14 / \mathrm{MWh}$ at maximum load. Dispatching this system to provide $1,020 \mathrm{MW}$ at minimum cost would request the full 1000 MW from the coal unit and $20 \mathrm{MW}$ from the combustion turbine.

The minimum-price dispatch, on the other hand, will run the combustion turbine at its full $100 \mathrm{MW}$ and back the coal plant down to $920 \mathrm{MW}$. Raising the combustion-turbine output from $20 \mathrm{MW}$ to $100 \mathrm{MW}$ raises the cost of providing the $1020 \mathrm{MW}$ of power by $\$ 1548 / \mathrm{hr}[(920 \mathrm{MW} \times \$ 14.40+100 \mathrm{MW} \times \$ 30.00)-(1000 \mathrm{MW} \times \$ 14.00+20 \mathrm{MW} \times$ $\$ 35.00)]$. The price paid for power, however, will drop by $\$ 5 / \mathrm{MWh}(\$ 35-\$ 30 / \mathrm{MWh})$ and the total payment for the $1020 \mathrm{MW}$ of power will drop by $\$ 5100 / \mathrm{hr}$. The coal unit's profits drop by one third, from $\$ 21,000$ to $\$ 14,352$.

These results suggest that the outputs from individual units can swing dramatically as the system load changes. As demand rises and it is necessary to bring on a new unit, that unit becomes the price-setter and is operated at full load to minimize the system price. What had been the most expensive unit (the previous price-setting unit) now goes from its maximum output to a much lower level to rebalance generation to load.

\section{ENERGY PLUS LOSSES}

The model then repeats the sequence of steps described above for energy to balance generation to load plus real losses for that hour. The user specifies an overall annual loss factor (e.g., 3\%). The model calculates losses for each hour based on an assumed quadratic relationship between losses and load:

$$
\text { Losses }=a \times(\text { Energy })^{2},
$$

where $a$ is a constant determined so that average losses equal the user input. 


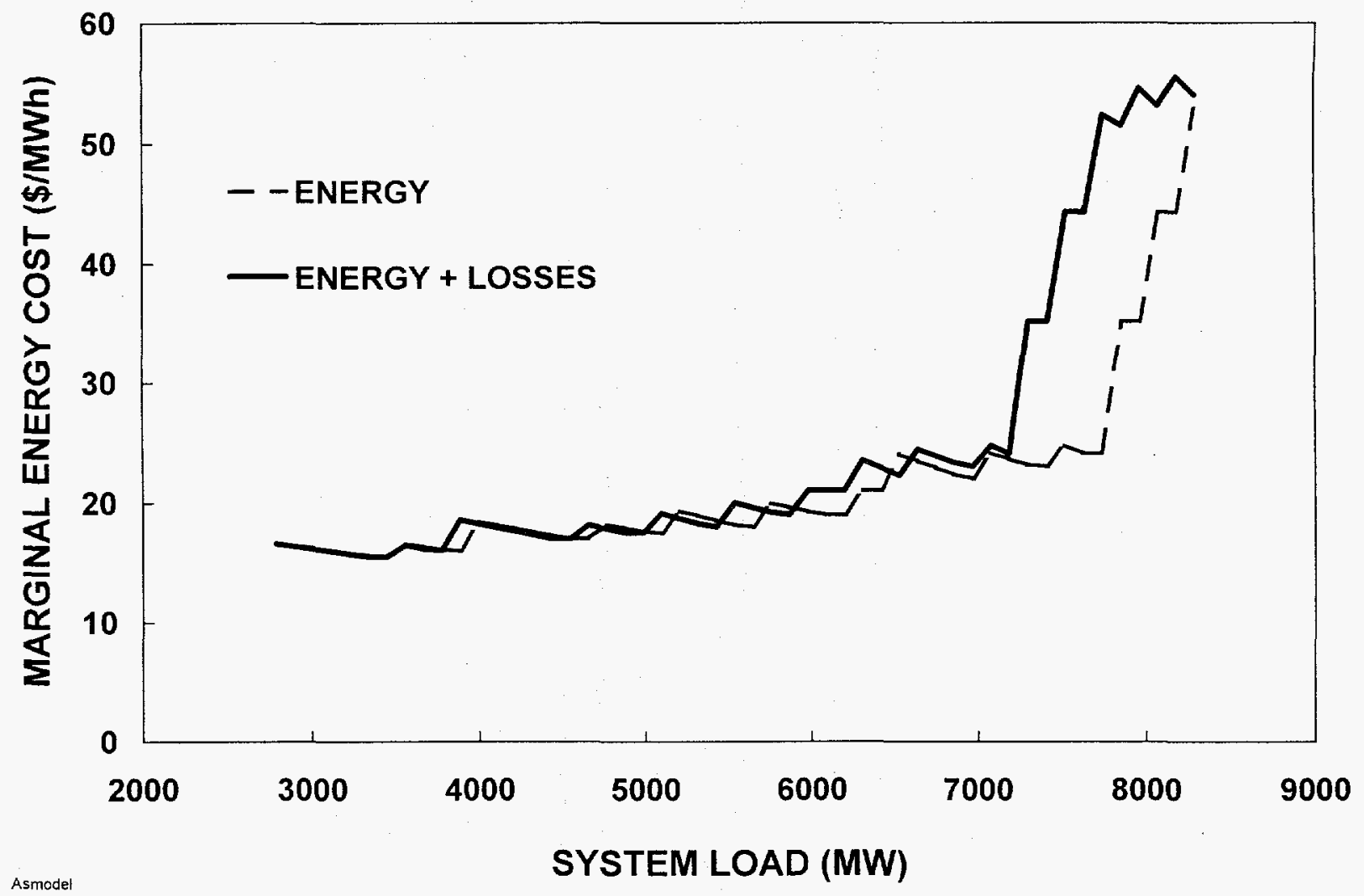

Fig. 4. Marginal costs for energy and for energy plus losses as functions of system load. The spot price is likely to be based on the marginal cost of energy plus losses.

Because losses require additional generator output, the cost of energy plus losses is usually higher, but occasionally lower, than the cost of energy only (Fig. 4). ${ }^{*}$ The prices of energy plus losses are lower than energy-only prices at low load levels where the must-run constraints apply or when the increased output does not require the start of another unit. In such situations, the increased output is obtained by operating the marginal unit at a higher output level, which leads to a lower marginal cost and, therefore, system price. Based on this final dispatch for energy plus losses, the model calculates the payments to each generator, the operating cost for each unit, and the unit's earnings for that hour.

Figure 5 shows the price of losses alone normalized to energy sales. The curve increases nonlinearly because both the amount of losses and the price of losses increase with increasing load (as shown by the formula above) and the spot price of energy plus losses in Fig. 4.

*The sawtooth pattern shown in Fig. 4 is, in part, a function of the small number of generators included in this model. A typical 10,000-MW system might have as many as 100 units, rather than the 25 in the present analysis. More units would reduce the lumpiness of results shown here. 


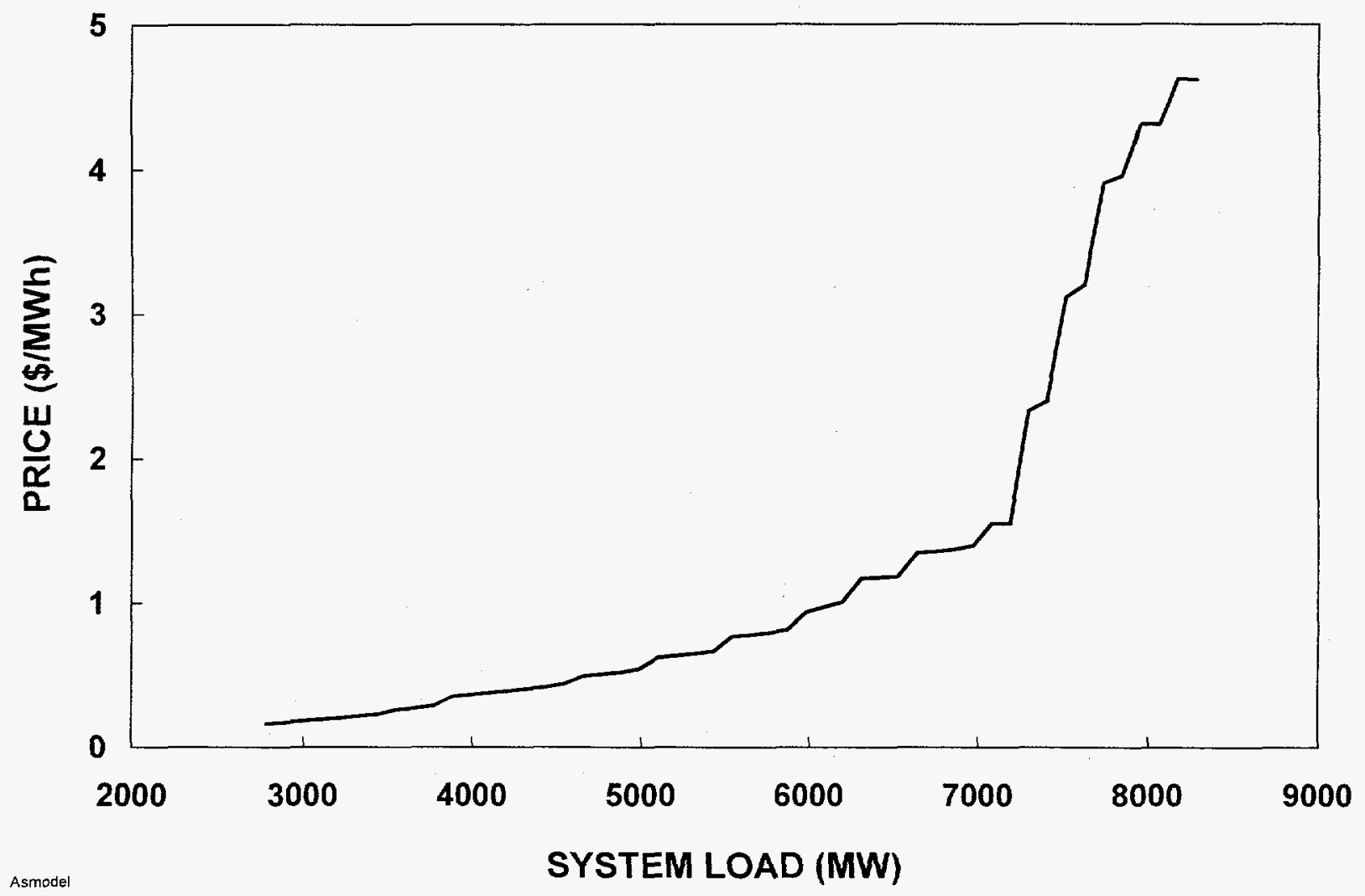

Fig. 5. Spot prices for losses (normalized to hourly load). The price increases rapidly at high levels of system load because spot prices are high (Fig. 4) and because losses increase with the square of the loads. 



\section{LOAD FOLLOWING}

Load following involves two factors. The first is the reservation of generating capacity for its later use. For example, during the morning hours, loads typically increase monotonically. The system load at the end of the hour might be $10 \%$ above the load at the beginning of the hour. Because generators have considerable thermal and process inertia, they cannot respond to such large load changes immediately. Thus, generation must be scheduled beforehand so that it is available to supply the load when needed. An analogous, but opposite, situation occurs during the afternoon dropoff when loads decrease.

The second factor is suboptimal dispatch of generators to meet the changing loads during the hour. During the morning pickup, to illustrate, the load at the beginning of the hour will be less than the hourly average. Temporarily redispatching generators to meet this lower load may affect production costs. Similarly, towards the end of the hour the load will be above the hourly average. Temporarily redispatching generators to meet this higher load may also affect costs. These redispatch costs are assigned to load following, not to the energy charges.

Figure 6 illustrates how our model handles these two factors. The load-following requirement varies from hour to hour during the course of a day, week, season, and year. During the typical diurnal cycle, the load-following requirements are at their minimum when the load is at its maximum or minimum values. For this analysis, we assumed that the loadfollowing requirement is invariant with system load and set to $5 \%$ of the average load.

We also had to simplify the physics of the situation because our model treats each hour separately; it does not treat the unit commitment of generators to meet the daily or weekly load cycles. For an average load of $100 \mathrm{MW}$, we assume a linear load-following requirement of $\pm 5 \mathrm{MW}$, from $-5 \mathrm{MW}$ at the beginning to $+5 \mathrm{MW}$ at the end of the hour. We compare the cost of dispatch at $95 \mathrm{MW}$ with that at $100 \mathrm{MW}$ for the first 15 minutes and the cost of dispatch at $105 \mathrm{MW}$ with that at $100 \mathrm{MW}$ for the final 15 minutes to calculate the redispatch cost assigned to load following.

Using the same approach used to dispatch for energy and losses, the model creates leastprice dispatches for Energy + Losses $+0.5 \times$ Load Following and for Energy + Losses $-0.5 \times$ Load Following. For each dispatch, the model computes the implicit spot price. The cost of load-following-induced redispatch is set equal to:

$$
0.25 \times\left[\left(\text { Price }_{\mathrm{LF}-\mathrm{up}}-\text { Price }_{\text {EnergytLosses }}\right)+\left(\text { Price }_{\mathrm{LF} \text {-down }}-\text { Price }_{\text {Energytlosses }}\right)\right] \times 0.5 \times \mathrm{MW}_{\mathrm{LF}} .
$$




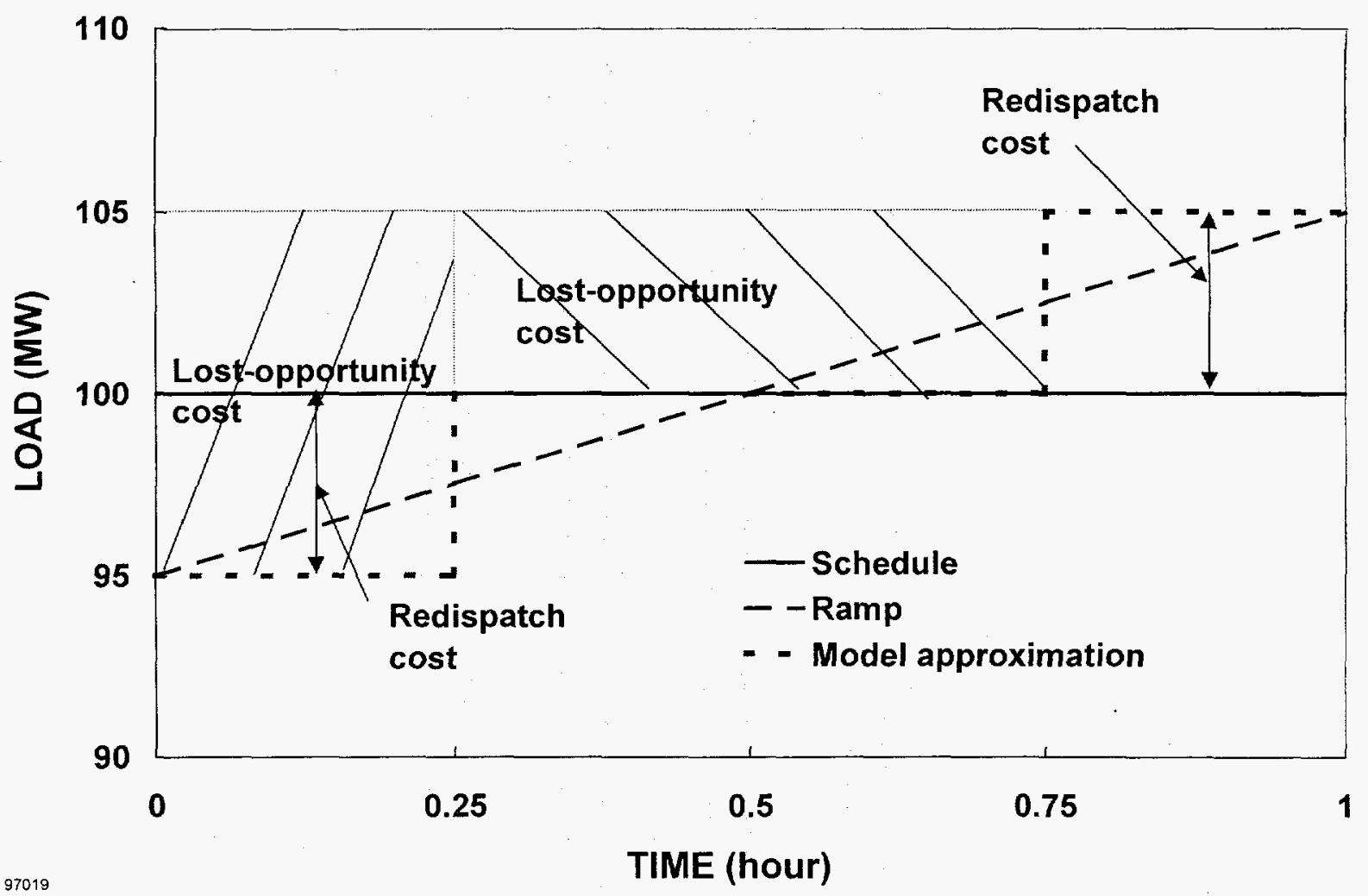

Fig. 6. Model representation of the load-following requirement within an hour and its redispatch and opportunity-cost components.

We calculate the opportunity cost (lost earnings) for those generators that lose profits when they are redispatched to meet either the high or low end of the load-following range. The loss is calculated for 0.5 hours for the units that lose money when redispatched to meet the top end of the load-forecasting range. In Fig. 6, this is the extra $5 \mathrm{MW}$ of generating capacity held in reserve for the first 45 minutes of the hour. We assume that the units redispatched down for the first 15 minutes lose their potential earnings both for this quarter hour plus the preceding hour. In both cases, the reference point is the upper end of the load-following range under the assumption that the units that provide load following forgo earnings associated with their highest output during the hour.

Figure 7 shows that the price of load following is quite erratic. (The curves for scheduling and energy imbalance are discussed in Chapter 9.) The sawtooth pattern is a function of the linear heat-rate curves assumed for each generator and the small number of units in this system (Fig. 3). The erratic nature of the curve between 7200 and $8000 \mathrm{MW}$ is a function of the opportunity cost associated with alternative uses of those generating units. 


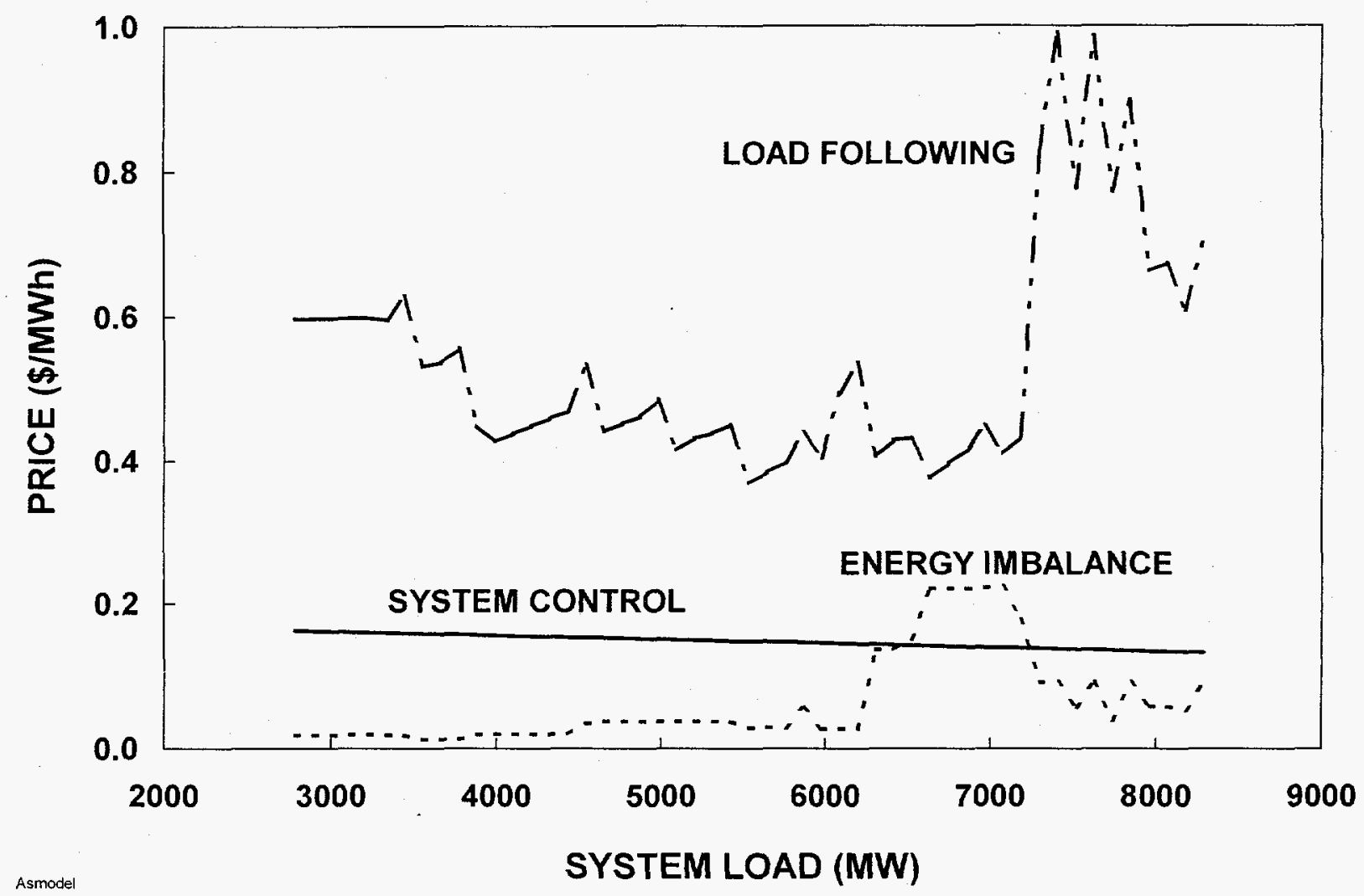

Fig. 7. Spot prices for load following, energy imbalance, and system control (normalized to hourly load).

When system load is $7200 \mathrm{MW}$, Unit 12 (a 450-MW coal unit) provides most of the increased capacity for load following. The difference between its variable cost $(\$ 23 / \mathrm{MWh})$ and the current spot price $(\$ 24 / \mathrm{MWh})$ is quite small. Unit 12 's opportunity and redispatch costs dominate and set the overall price for load following at $\$ 13 / \mathrm{MW}$.

When system load is $100 \mathrm{MW}$ higher, Unit 13 (a 300-MW coal unit) provides most of the increased capacity for load following. The difference between its variable cost $(\$ 26 / \mathrm{MWh})$ and the current spot price $(\$ 35 / \mathrm{MWh})$ is almost ten times larger than when system load was $7200 \mathrm{MW}$. Unit 13 's opportunity costs dominate the price of load following, $\$ 25 / \mathrm{MW}$ in this case.

The spot price at $7300 \mathrm{MW}$ is so much higher than at $7200 \mathrm{MW}$ because of differences in the price-setting unit at the two load levels. At $7200 \mathrm{MW}$, Unit 13, with variable plus startup costs of $\$ 24 / \mathrm{MWh}$, is the marginal unit. At $7300 \mathrm{MW}$, Unit 14 , a combined-cycle unit with variable plus startup costs of $\$ 35 / \mathrm{MWh}$, is the price-setting unit.

The reverse situation occurs when load increases from 7900 to $8000 \mathrm{MW}$. At $7900 \mathrm{MW}$, Unit 15 operating at $\$ 44 / \mathrm{MWh}$ sets the load-following price. The spot price at this load is 
$\$ 52 / \mathrm{MWh}$. At $8000 \mathrm{MW}$, Unit 16 operating at $\$ 52 / \mathrm{MWh}$ sets the load-following price. The spot price at this load is almost the same as at $7900 \mathrm{MW}, \$ 54 / \mathrm{MWh}$. However, at $8000 \mathrm{MW}$, the difference between the variable cost of the load-following unit and the spot price is much less than at $7900 \mathrm{MW}(\$ 52-\$ 54=-\$ 2$ vs $\$ 44-\$ 52=-\$ 8)$. Thus, the price of load following is much lower at 8000 than at $7900 \mathrm{MW}(\$ 22$ vs $\$ 31 / \mathrm{MW})$.

As for the other ancillary services, the model calculates unit-specific revenues, costs, and earnings. Because of the redispatch costs, the price paid to generators for providing load following is often less than the price paid by customers to the system operator for this service. 


\section{REGULATION}

Regulation is the service that follows moment-to-moment fluctuations in system load. Measuring the performance of units on regulation requires consideration of three factors: (1) the amount of regulation (MW) provided, (2) the speed at which the unit's output is changed (MW/minute), and (3) the number of direction changes (from increasing to decreasing and from decreasing to increasing per hour).

Regulation may involve five cost components:

- Heat-rate penalty: Frequently adjusting the output of a generator increases the amount of fuel used relative to the situation in which the unit runs at a constant output.

- Increased operations and maintenance costs: The changes in unit output from minute to minute increase wear and tear on the unit.

- Shorter unit lifetimes: The changes in output from minute to minute shorten the operating lifetime of the unit because parts will wear out faster than if the unit was operated at constant output. (This factor may be reflected primarily in greater long-term operations and maintenance costs rather than in an actual reduction in unit life.)

- Opportunity cost: It may be necessary to reduce the energy output for some units already online and operating at or near their maximum loadings. Such reductions are needed to provide regulation headroom at those units or to provide footroom at other units. These units will lose money based on the difference between the current price of energy and their variable (fuel plus operations and maintenance) costs multiplied by the reduction in energy output. This opportunity cost should be assigned to regulation.

- Unit commitment: It may be necessary to operate some units (i.e., less efficient units) to provide energy to offset the reduced energy output from other units that are providing regulation. This redispatch out of merit order increases the costs to produce energy. The same phenomenon will occur for a unit that would otherwise operate near its minimum loading point but has its energy output increased to provide regulation footroom.

"Headroom refers to the operation of the unit below its maximum level to allow for the unit's response to automatic-generation-control signals that request increases in output within the regulating band that the unit is providing. Similarly, footroom refers to the operation of the unit above its minimum level to allow for the unit's response to control signals that request decreases in output. 
Little literature exists on these cost components to provide regulation.

For purposes of our model, we characterized individual generators in terms of their maximum 10-minute ramp rate and their regulating penalty, in $\$ / \mathrm{MW}$-regulation, intended to capture the first three of the five factors identified above. User inputs to the model specify the amount of regulation required as a percentage of hourly load, the minimum number of generators across which this regulation must be spread, and the number of minutes within which this regulation capacity must be able to respond (e.g., within five minutes, which implies that only half of the 10-minute-ramp-rate capability would be available for regulation). The model's calculations determine the costs for the last two factors listed above.

Calculation of the cost of regulation and its assignment to individual generators begins with the energy-plus-loss dispatch (Chapter 4). The model determines how much regulating capacity is available from each unit then online, based on its regulating ramp rate and its current output (which determines the amount of regulating head- and footroom available). The amount of regulation available is capped at the lesser of:

- the unit's regulation-ramping capability,

- the maximum amount of regulation that can be assigned to any single unit,

- the difference between the unit's maximum capacity and operating point at the end of the energy-plus-loss dispatch, and

- the difference between the unit's level at the end of the energy-plus-loss dispatch and the unit's minimum operating point.

For units not online, the model considers the full regulating ramp rate to be available. The model then calculates the cost of regulation for each unit, based on its regulating penalty and its opportunity cost. "If the units online are unable to provide sufficient regulating capacity (i.e., another unit must be started to meet energy-plus-losses-plus-regulation requirements), then the regulation bid from the least expensive unit that would be started to provide regulation is adjusted down to reflect the fact that it must be started and operated at its minimum loading point plus its regulating margin. This unit is paid its full costs to start up and operate at a loss relative to the current spot price; however, the other units that bid to supply regulation are not paid for these redispatch costs.

The regulation bids are ordered from lowest to highest. The bids are accepted in order of increasing costs until sufficient regulating capacity has been acquired, subject to the constraint that the regulation is spread across the user-specified minimum number of units. The

${ }^{*}$ The opportunity cost is the potential earnings loss the generator would experience if it provided regulation instead of the energy it had contracted to provide in the energy-plus-loss market (Fig. 1). 
supplier price for regulation, what suppliers receive for providing this service, is the bid from the most expensive unit whose output was accepted by the system operator.

At this point, the system is likely to be out of balance with respect to energy plus losses, because of the headroom and footroom requirements associated with provision of regulation. The model then redispatches generation up or down to (1) match generation to demand plus losses, (2) respect minimum loading points (adjusted up to allow for regulating footroom, including consideration of must-run units), and (3) respect maximum loading points (adjusted down to allow for regulating headroom). The final result is balanced energy output. The cost of this redispatch (reflected in a new implicit market-clearing price) is generally higher than the original price associated with energy plus losses. Any earnings losses associated with this redispatch is paid to those generators whose units are redispatched for regulation. This extra cost of redispatch is assigned to regulation and collected from customers as part of the price for regulation that they pay. In other words, the price of regulation to customers is typically higher than the price paid to suppliers, with the difference paid to those generators whose units were redispatched to maintain the hourly generation/load balance subject to the head- and footroom constraints for the units on regulation.

The redispatch of generating units to satisfy requirements for regulation (as well as spinning reserve, discussed below) is consistent with some of the independent system operator proposals. The New York Power Pool (1997) states:

On some occasions in the real-time market, the ISO may operate generators on dispatch below economic levels in order to maintain proper levels of reserves. In these instances, all generators on dispatch providing spinning reserve will be paid the market price of spinning reserve, defined as the greatest lost opportunity cost among these generators. The lost opportunity cost for a generator will be calculated as the difference between its energy bid and the [location-based marginal price] at its location.

The PJM proposal (Atlantic City Electric et al. 1997) has similar language.

Finally, the model calculates the payments to each generator for the regulation it provides, the costs to each generator for providing this service, and the generator earnings from regulation (i.e., the unit-specific differences between payments and costs).

Figure 8 shows the system cost of regulation normalized to energy sales. (The curves for spinning and supplemental reserves are discussed in Chapter 7.) The erratic nature of the curve is a function of the opportunity cost associated with alternative uses of those generating units that provide regulation at various points along the load-duration curve. The regulation penalty, intended to reflect the direct fuel, operations, and maintenance costs of regulation, account for about $40 \%$ of the annual price of regulation; redispatch and opportunity costs account for the other $60 \%$. 
At a system load of $3309 \mathrm{MW}$, Units 1 through 4 provide energy plus losses. To meet the regulation requirement that no more than $26 \mathrm{MW}$ is obtained from any one unit, Unit 5 is turned on to provide both energy and regulation. The supplier price of regulation at this load is set by Unit 1 at $\$ 11 / \mathrm{MW}$. Redispatch payments account for about half the cost to customers and total $\$ 22 / \mathrm{MW}$.

Adding one MW to system load requires that one more unit be brought online (Unit 7 in this case) to meet the regulation constraints. (Unit 7, rather than the cheaper Unit 6 , is the incremental unit because its minimum load is $90 \mathrm{MW}$ compared with $150 \mathrm{MW}$ for Unit 6.) This unit's bid price for regulation, which excludes its startup costs, sets the supplier price for regulation at $\$ 24 / \mathrm{MW}$. Redispatch costs are slightly higher than before, bringing the customer cost of regulation to almost $\$ 39 / \mathrm{MW}$. Thus, a $1-\mathrm{MW}$ increase in system load leads to a near doubling of regulation costs. In this example, the model does not recognize that Unit 4 (with a capacity of $850 \mathrm{MW}$, dispatched at $834 \mathrm{MW}$ to meet energy plus load plus $16 \mathrm{MW}$ for regulation) was ultimately redispatched down to provide regulation footroom for other units. This downward redispatch freed up capacity on Unit 4 that could have been assigned to regulation, eliminating the need to turn on Unit 7. This example demonstrates the complexities that can arise in system-operator decisions to dispatch and redispatch generating units. How many iterations should the system operator be allowed to perform (Exhibit 2)?

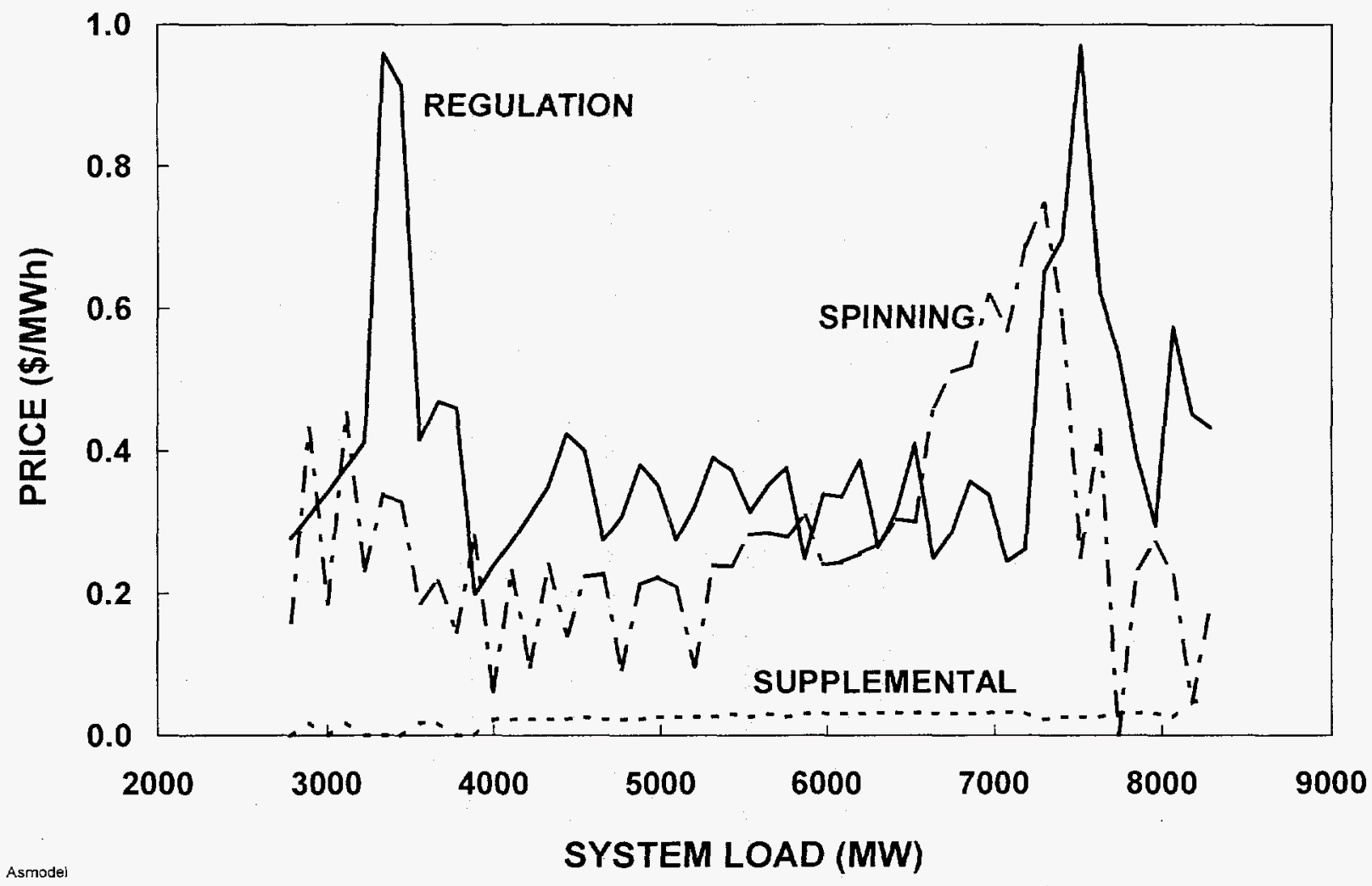

Fig. 8. Spot prices for regulation, spinning reserve, and supplemental reserve (normalized to hourly load). 


\section{Exhibit 2. System operator authority to redispatch generators}

Granting the system operator permission to move units to facilitate acquisition of ancillary services at cost seems like a good idea, but it could cause controversies. Difficulties might arise because such mandated redispatches could affect the profits of individual generators.

Extending the previous example of the two-generator system, suppose that the system operator needs $10 \mathrm{MW}$ of regulation from each of the generators. If the system operator is allowed to move the combustion turbine from $100 \mathrm{MW}$ to $90 \mathrm{MW}$ (and move the coal unit from $920 \mathrm{MW}$ to $930 \mathrm{MW}$ to maintain the energy balance) at cost to provide headroom on the combustion turbine, the system will save approximately $\$ 160 / \mathrm{hr}[10 \mathrm{MW} \times(\$ 30-$ $\$ 14 / \mathrm{MWh})$ ]. This cost savings is associated with moving production from the expensive combustion turbine to the cheaper coal unit.

This cost difference gives the system operator an incentive to move as much production as possible from the combustion turbine to the coal unit. Although such shifts in production would not create an absolute loss for the coal unit, they will reduce profits relative to what they would otherwise have been. The owner of the coal unit will complain about such movements in output unless they are clearly required to meet regulation and spinning-reserve requirements.

One possible solution would be to pay the generator the greater of its cost or the current price of energy. But even this is not quite correct. Had the combustion turbine been forced to bid into the energy market at $90 \mathrm{MW}$ instead of $100 \mathrm{MW}$ the clearing price for energy would have been $\$ 30.63$ instead of $\$ 30.00$. This would have resulted in an increase of $\$ 580 / \mathrm{hr}$ in the coal unit's profit. The situation becomes more complex and the potential for economic disparity rises as the number of units and services is increased. An alternative approach would have the units self-constrain their energy bids if they want to bid into ancillary-service markets. With this type of market structure, the system operator could redispatch units only in emergencies.

In principle, the system operator should be allowed to move generators up or down at cost to facilitate reliability. This may be difficult to implement. If moving a generator would change its bid price to supply energy, this could increase what would otherwise have been the market price for energy. While the unit that was moved may be indifferent to this change, the other units will want to see the higher energy price established as the market clearing price. The system operator may be required to demonstrate that the shift in generator output was required exclusively for reliability. 



\section{OPERATING RESERVES}

\section{SPINNING RESERVE}

The model analyzes the spinning-reserve market in much the same way that it analyzes the regulation market with three differences:

- Provision of spinning reserve requires headroom but not footroom. That is, units cannot be providing energy at their maximum-output levels but they can run at their minimumoutput levels.

- We assume that there is no operating penalty associated with the provision of spinning reserve capacity. ${ }^{*}$ [Of course, when a unit is called upon to provide output when a generator or transmission line trips offline, then it incurs fuel plus other variable costs; these costs are not considered here because they are incurred only rarely (Hirst and Kirby 1997).] Thus, the only cost to the generator to provide spinning reserve is the opportunity cost associated with foregone energy sales.

- The dispatch of generators to provide spinning reserve must recognize the prior use of some ramping capability for regulation and the head- and footroom requirements associated with provision of regulation.

Analysis of spinning reserve begins with the energy and regulation dispatches of all generators at the close of the regulation market. The amount of spinning reserve available from each generator is based on its 10-minute ramp rate, adjusted down for the amount of regulation provided from each unit. For units not online, the model considers the full ramp rate to be available. If the units online are unable to provide sufficient spinning reserve, then the spin bid from the least expensive unit that would be started to provide spinning reserve is adjusted down to reflect the fact that it must be started and operated at its minimum loading point. As with regulation, the other units that supply spinning reserve are not paid for these startup and minimum-load operating costs.

"Generators that provide spinning reserve run with their steam-turbine valves only partially open to permit the valves to open fully when frequency drops and the governor calls for more turbine-generator output (Curtice 1997). Operation with valves not fully open is less efficient than operating with valves wide open, but such operation permits rapid response to generator or transmission contingencies. 
As with regulation, the spin bids are ordered from lowest to highest. The bids are accepted in order of increasing costs until sufficient spinning reserve has been acquired, subject to the constraint that this reserve be spread across the user-specified minimum number of units. The supplier price for spin is then the bid from the most expensive unit whose output was accepted by the system operator.

At this point, the system is likely to be out of balance with respect to energy plus losses because of the headroom requirements associated with spinning reserve. The model then redispatches generation to meet the original energy-plus-loss requirement, respecting the minimum and maximum loading points for those units that are providing regulation and/or spinning-reserve services that hour. This redispatch cost (reflected in the implicit marketclearing price) is generally higher than the original price associated with energy plus losses plus regulation. Any earnings loss associated with this redispatch is paid to those generators whose units are redispatched for spin. This extra cost of redispatch is assigned to spin and collected from customers as part of the price for spin that they pay. In other words, the price of spin to customers is typically higher than the price paid to suppliers, with the difference paid to those generators whose units were redispatched to maintain the hourly generation/load balance subject to the head- and footroom constraints for those units providing regulation and those units providing spinning reserve.

Finally, the model calculates the payments to each generator for the spinning reserve it provides, the costs to each generator for providing this service, and the generator earnings from spinning reserve (i.e., the unit-specific differences between payments and costs).

Figure 8 shows the price of spinning reserve normalized to energy sales. The erratic nature of the curve is a function of the opportunity cost associated with alternative uses of those generating units that provide spin at various points along the load-duration curve. Spinning reserve is generally less expensive than regulation; for the base case analyzed here, the annual cost of spinning reserve is about two-thirds that of regulation. This difference occurs primarily because of the operating costs associated with regulation. Unlike spinning reserve, which is called upon to provide energy only rarely, units on regulation are constantly moving up or down. This difference is reflected in the heat-rate penalty associated with regulation and with the regulation requirement for reserves that can respond fully within five minutes vs the tenminute requirement for spinning reserve.

The process of balancing the markets for energy, energy plus losses, regulation, and spinning reserve requires substantial discretion on the part of the system operator. As noted in Exhibit 3, allowing the system operator to redispatch individual units can create problems. 


\section{Exhibit 3. When should the system operator make public the results of each market?}

It is not clear when it is appropriate to "lock in" the dispatch at the close of each market. The energy being requested from a unit may be moved up or down to meet ancillary-service requirements even if that unit is not selling any ancillary services. A $600-\mathrm{MW}$ unit that is scheduled to generate $300 \mathrm{MW}$ for the energy market might get moved to $330 \mathrm{MW}$ to facilitate the purchase of regulation from another unit that was previously scheduled at its maximum output. Alternatively, the $600-\mathrm{MW}$ unit could be moved to $210 \mathrm{MW}$ to facilitate the purchase of regulation from a unit that is turned on and operated at minimum output plus footroom to provide regulation. These movements could be independent of whether a particular unit was selling regulation or not. It is not clear that this unit is entitled to any profits associated with such redispatches, especially because its redispatch may change from one market to another. It might be best for the system operator to wait until all of the ancillary-service markets close to disclose any of the dispatches. Alternatively, the system operator could request incremental and decremental bids from suppliers and customers, which would allow it to choose the least-cost way to redispatch.

\section{SUPPLEMENTAL RESERVE}

The market for supplemental reserve operates immediately after closure of the spinningreserve market. Because the units that provide supplemental reserve need not be operating, the treatment of this service is simpler than that for regulation or spinning reserve.

User inputs to the model specify the hourly cost (in $\$ / M W$ ) to provide supplemental reserve if the unit is not already running. These costs are primarily those associated with having plant operators on location ready to turn the unit on if an outage occurs. If the unit is already running, we assume that the unit has no incremental cost to provide supplemental reserve and therefore bids a zero price for this service. The user also inputs startup 10-minute ramp rates for each unit, intended to reflect the amount of capacity that can be made available within 10 minutes when the unit is initially not running. Our inputs to the model are such that these values are all less than or equal to the regulation and spinning-reserve 10 -minute ramp rates.

The model sorts the bids in increasing order and selects winners beginning with the cheapest (usually from those units that are already operating but not fully loaded) until enough supplemental reserve has been acquired. As with regulation and spinning reserve, the supplemental reserve must be spread across a user-specified minimum number of units.

Finally, as with the other services described above, the model calculates the payments, costs, and earnings for each generator that provides supplemental reserves. 
Figure 8 shows the cost of supplemental reserve normalized to energy sales. The curve generally increases with increasing load. Supplemental reserve is much cheaper than either regulation or spinning reserve, primarily because it involves very little operating cost and no opportunity cost. 


\section{VOLTAGE CONTROL}

User inputs to the model specify the reactive-power requirement at an average realpower level (e.g., $950 \mathrm{MVAR}$ at $6000 \mathrm{MW}$ ), the price paid to generators for provision of reactive support, and the design power factor for each of the generating units (usually 0.85 or 0.90 ). Our model ignores the location dependence of voltage-support requirements as well as transmission provision of voltage support.

Our analysis of reactive losses in transmission lines of different sizes (ranging from 69 to $500 \mathrm{kV}$ ) shows that reactive losses increase roughly with the cube of real-power flows. We used this relationship to determine the reactive-power requirements for each level of real power analyzed.

The model calculates the reactive-power requirement from each generator by assigning each generator a share of the system's requirement based on the ratio of the unit's real-power output that hour to the system's total real-power output.

If a generator is operating at or near its maximum real-power-output level and the amount of reactive power needed exceeds that available at its design power factor, then the unit will have to reduce its real-power output to meet its reactive requirements. In such situations, the unit experiences an opportunity cost associated with the foregone real-power production." (This situation occurs only at high levels of demand approaching the annual system peak.) The model calculates the earnings loss to each generator that forgoes energy production to produce more reactive output. In addition, the model calculates the extra cost of producing this realpower output from more-expensive units. These two costs are added to the basic reactive-power payments to generators to yield the total cost of voltage control to customers.

Because of the opportunity costs described in the preceding paragraph, the cost of voltage control is highly nonlinear with energy. Voltage-control costs increase slowly with increasing real-power demand over much of the annual range in real-power demand. However, as demands approach the annual peak, the opportunity cost quickly dominates the overall cost.

${ }^{*}$ Data we collected from 12 utilities suggest an average cost of $\$ 0.20 / \mathrm{kW}$-month. Curtice (1997), on the basis of a review of 20 utility filings, estimates an average cost of $\$ 0.17 / \mathrm{kW}$-month.

"We assume constant apparent power (MVA) output from the generator, which determines the tradeoff between increased reactive-power output and reduced real-power output. 
Figure 9 shows the cost of voltage control; the graph shows the total cost as well as the cost without the opportunity cost associated with reduction in real-power output to meet highload reactive-power requirements. This opportunity cost, zero below about $7700 \mathrm{MW}$, increases dramatically at high loads. Over the course of a year, the lost earnings associated with reduced real-power output from generators accounts for $16 \%$ of the total cost of generator-related voltage control in this example.

The model also calculates the payments to each generator for voltage control, the costs to provide this service (i.e., the opportunity cost associated with foregone profits from selling energy), and the generator-specific earnings.

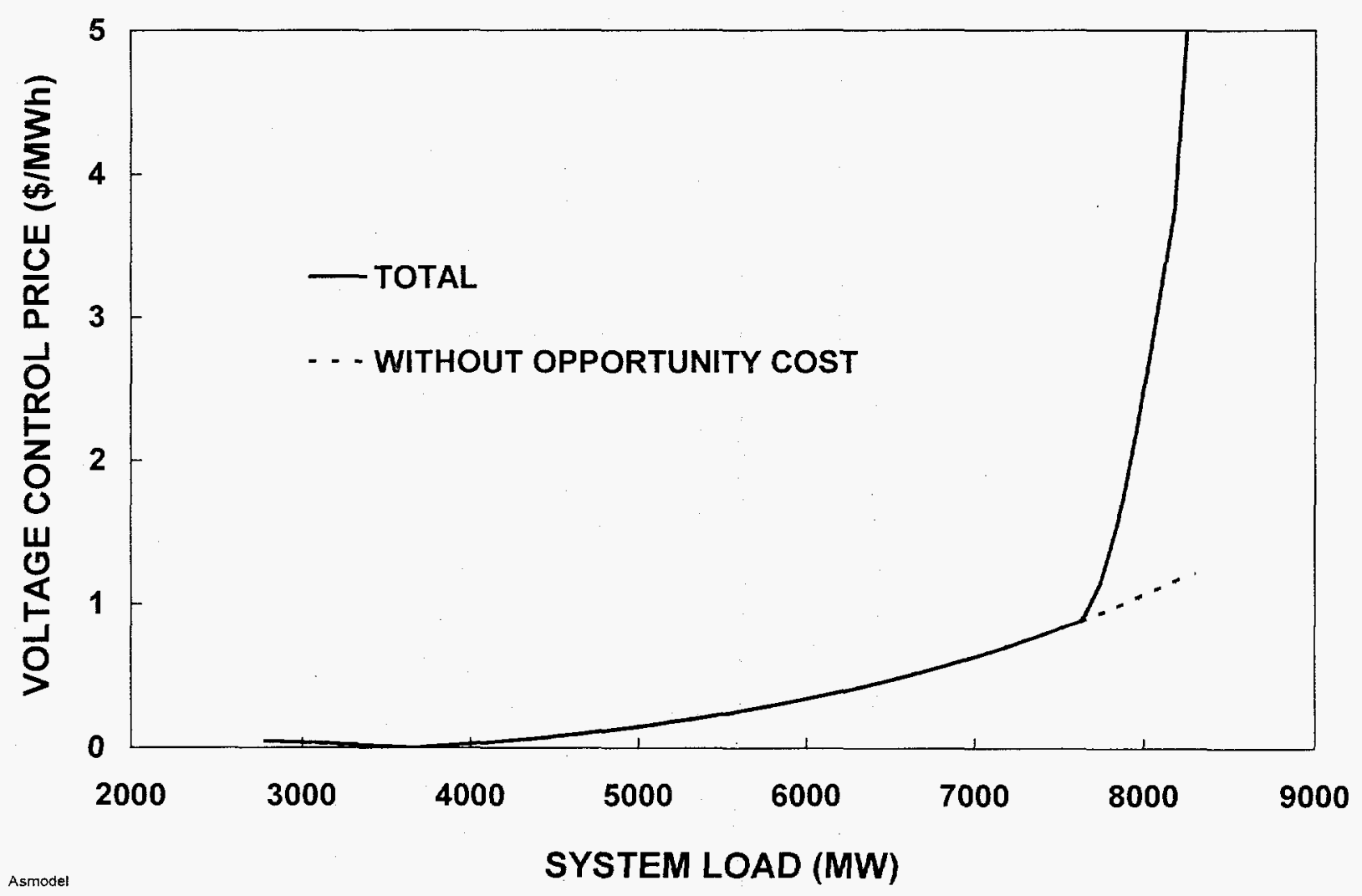

Fig. 9. Spot prices for voltage control (normalized to hourly load). 


\section{ENERGY IMBALANCE AND SYSTEM CONTROL}

We treat these services together, not because of any similarity in their function or provision, but because the model treats them in a very simple way. That is, no unit-specific analysis is done for either service. This simplification is reasonable for system control because it is not a generation-related service. This simplification is less reasonable for energy imbalance but rests on our belief that generators providing this service will recover their costs but make little profit from the sale of energy-imbalance services.

\section{ENERGY IMBALANCE}

The user specifies the amount of energy imbalance expressed as a percentage of the hourly load (e.g., $2 \%$ in the base case).

The model calculates incremental and decremental energy costs for energy imbalance. The incremental cost is that associated with turning on the next most expensive generating unit. The decremental cost is that associated with operation of the inframarginal unit. These calculations are performed upon closure of the spinning-reserve market and are based on the generation dispatched to meet energy, losses, regulation, and spinning reserve.

We assume that net imbalances will sometimes be positive (overgeneration) and sometimes be negative (undergeneration) with equal probabilities. Net imbalances refer to the system imbalance, the algebraic sum of the individual imbalances associated with each transaction. We assume that (1) transactions that involve excess generation will be compensated for at the current energy-imbalance price and (2) transactions that involve undergeneration will pay for their imbalances at the current energy-imbalance price. The current imbalance price will be that associated with the incremental unit when the system as a whole is deficient (undergeneration), and the imbalance price will be that of the decremental unit when the system is surplus (overgeneration).

We do not redispatch individual generators to meet assumed energy-imbalance conditions. Rather we calculate, as described above, the overall cost of such imbalances. Because our treatment of this service involves the system as a whole rather than individual units (in an effort to simplify the structure of this model), we are not able to calculate generatorspecific revenues, costs, or earnings for energy imbalance. Thus, our later discussion on the profitability of ancillary services excludes energy imbalance. 
Figure 7 shows the cost of energy imbalance normalized to energy sales. The curve generally increases, although erratically, with increasing load.

\section{SYSTEM CONTROL}

We include system control for completeness even though it is not provided by generating units and is not a competitive service. We obtained data from 12 utilities on their costs of ancillary services, including scheduling and system control (Kirby and Hirst 1996).

These data show that system-control costs per MW of peak load decrease with the size of the utility system. We arbitrarily applied this declining-cost relationship to the cost of scheduling hour-by-hour during the year. Figure 7 shows a decline in system-control cost per MW as loads increase. 


\section{RESULTS}

The preceding seven chapters explained how the model works, both in general and for each ancillary service. This chapter presents results from the model for the base-case system developed for this study. These results would be different, perhaps substantially different, if we had used a different mix of generating units and different assumptions concerning the amounts of each service required and the cost components for each service.

As indicated throughout this report, the prices of ancillary services are closely tied to the overall system load and, therefore, to the spot prices for energy. Indeed, the correlation coefficient $(r)$ between the price of ancillary services in aggregate and the price of energy is 0.96, which implies that the price of energy alone explains $91 \%$ of the variation from hour to hour in the price of ancillary services in aggregate. Figure 10 shows that the overall price of ancillary services increases in a near-monotonic fashion with system load, from a low of about $\$ 1 / \mathrm{MWh}$ at $2800 \mathrm{MW}$ to a high of $\$ 14 / \mathrm{MWh}$ at the 8300 -MW system peak. Averaged over the year, the set of eight ancillary services considered here cost the equivalent of $\$ 2.3 / \mathrm{MWh}$, more than $10 \%$ of the average energy price of $\$ 19.9 / \mathrm{MWh}$. By comparison, the production-weighted spot price of electricity in the PJM Interconnection averaged \$24/MWh between April and July 1997 (PJM Interconnection 1997).

Figure 11 shows the contribution of ancillary services to total costs and producer profits as a function of system load. In aggregate, ancillary-service costs increase more rapidly than do energy prices with system load as shown by the increasing share of total costs contributed by ancillary services. At low levels of system load, ancillary services account for less than $10 \%$ of total costs. But at high levels of load, ancillary services account for 15 to $20 \%$ of total costs. The pattern with respect to the profits generated by selling ancillary services shows the same upward trend with system load that costs do. However, the pattern is much more erratic. Averaged over the full year, ancillary services account for $12 \%$ of total generator profits.

Table 2 shows the distribution of ancillary-service costs among the services analyzed here. Losses, representing about one third of the total, is the most costly service. [Our analysis of the embedded-cost tariffs that 12 utilities filed with FERC also showed losses as the most costly service (Kirby and Hirst 1996).] Load following is the second most costly service. On the other hand, energy imbalance and supplemental reserve are the least costly services, accounting for only 1 to $2 \%$ each. The prices of these services generally increase in going from low to average to high load levels. Load following and system control are the key exceptions to this observation. 


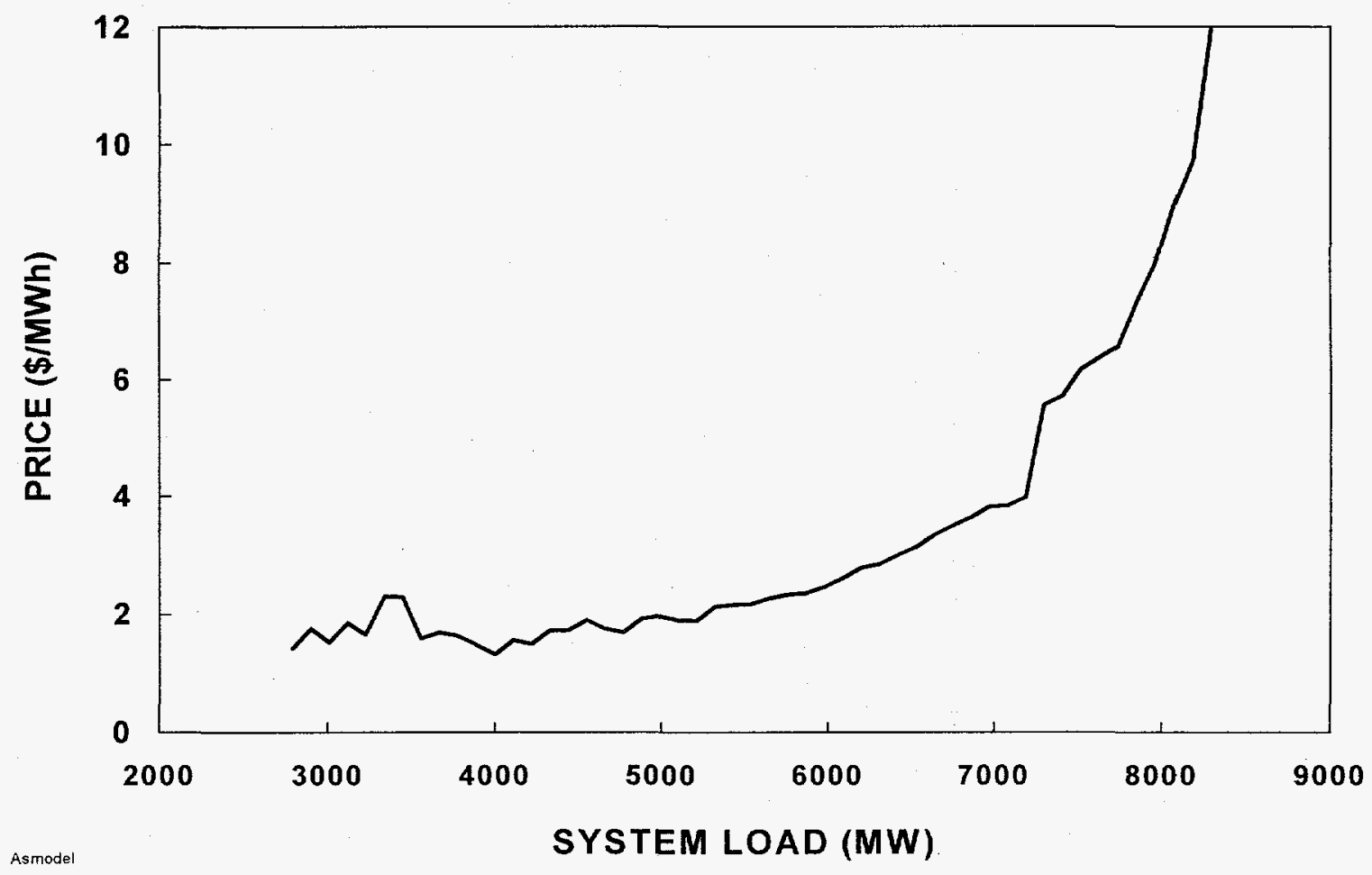

Fig. 10. The cost to consumers for the eight ancillary services analyzed here.

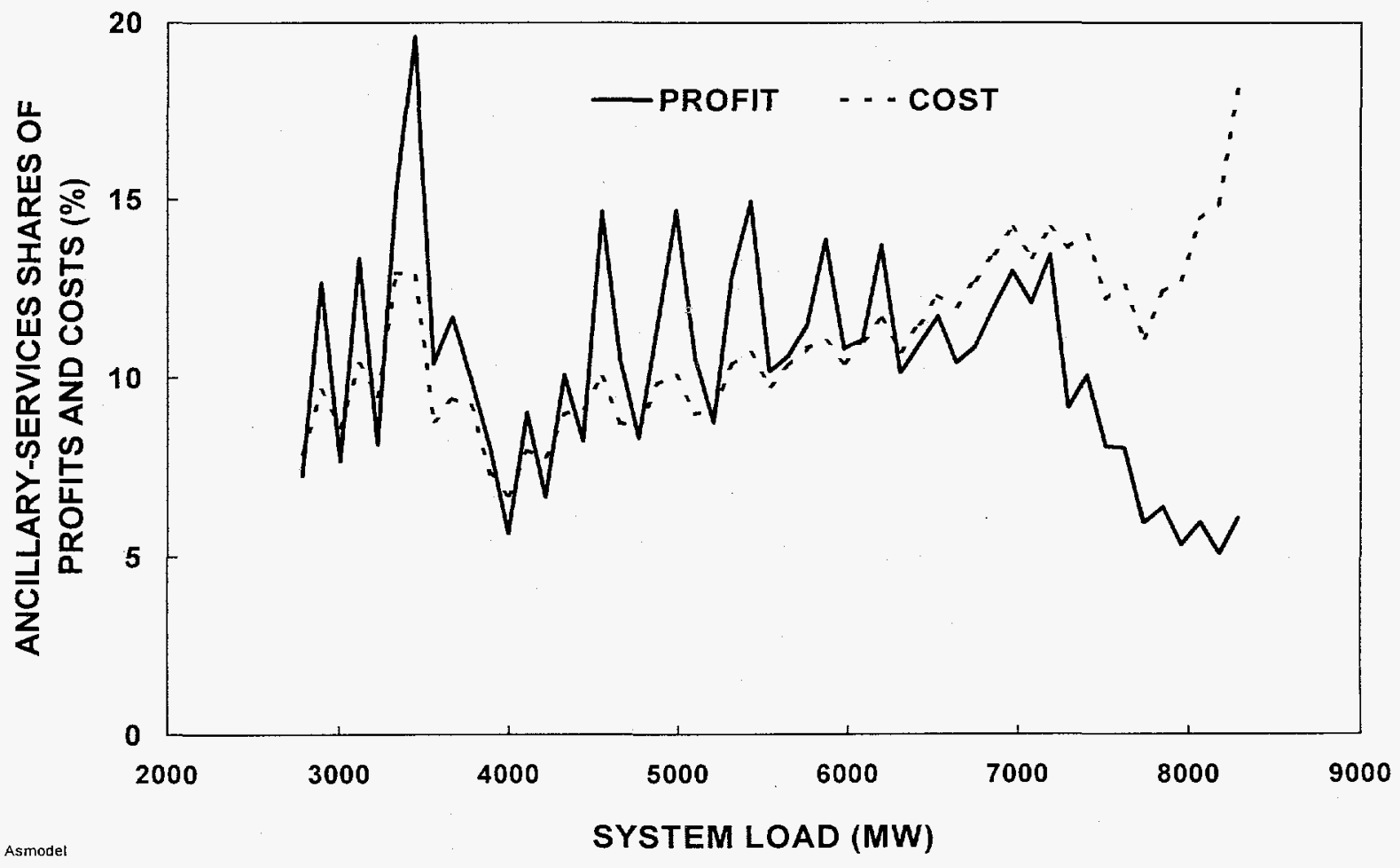

Fig. 11. The contributions of ancillary services to total generator costs and profits. 
Several of the graphs presented above show erratic patterns. This is, in large part, a consequence of the need to redispatch individual generators in going from energy to energy plus losses to regulation and to spinning reserve. Figure 12 shows, for a system load of 5000 MW (and a system requirement of $5155 \mathrm{MW}$ for energy plus losses), the changes in dispatch for four generators. (Generators 1 through 6 are fully loaded in all cases.)

To provide enough generation for energy plus losses, Unit 7 operates at $168 \mathrm{MW}$, and Unit 8 operates at $287 \mathrm{MW}$. To provide the required $100 \mathrm{MW}$ of regulation spread across at least three units, Unit 8 is redispatched from 287 to $133 \mathrm{MW}$, and Unit 9 is turned on and operates at $154 \mathrm{MW}$. Units 7,8 , and 9 each provide $33 \mathrm{MW}$ of regulation. To provide the required $150 \mathrm{MW}$ of spinning reserve spread across at least four units, Unit 9 is redispatched from 154 to $143 \mathrm{MW}$, and Unit 10 is turned on and operates at $60 \mathrm{MW}$. Those with a sharp pencil may notice that the numbers do not add up for spinning reserve; Unit 6 is redispatched down from its maximum output of $750 \mathrm{MW}$ to $745 \mathrm{MW}$. Units 7, 8, 9, and 10 each provide 37.5 MW of spinning reserve.

Table 2. Ancillary-service prices (normalized to hourly load levels) and distributions for low, average, and high levels of system load. ${ }^{a}$

\begin{tabular}{|c|c|c|c|c|c|c|}
\hline & \multicolumn{2}{|c|}{$\begin{array}{l}\text { Bottom 10\% } \\
\text { (3520 MW, } \\
\$ 16.3 / \mathrm{MWh})\end{array}$} & \multicolumn{2}{|c|}{$\begin{array}{c}\text { Average } \\
\text { (4910 MW, } \\
\$ 19.9 / \mathrm{MWh})\end{array}$} & \multicolumn{2}{|c|}{$\begin{array}{c}\text { Top 10\% } \\
\text { (6910 MW, } \\
\$ 28.2 / \mathrm{MWh})\end{array}$} \\
\hline & $\$ / \mathrm{MWh}$ & $\%$ & $\$ / M W h$ & $\%$ & $\$ / M W h$ & $\%$ \\
\hline Losses & 0.25 & 16 & 0.75 & 33 & 1.78 & 41 \\
\hline Regulation & 0.42 & 27 & 0.35 & 15 & 0.38 & 9 \\
\hline Spinning reserve & 0.17 & 11 & 0.24 & 10 & 0.42 & 10 \\
\hline $\begin{array}{l}\text { Supplemental } \\
\text { reserve }\end{array}$ & 0.00 & 0 . & 0.02 & 1 & 0.03 & 1 \\
\hline Load following & 0.54 & 35 & 0.47 & 20 & 0.50 & 12 \\
\hline Energy imbalance & 0.01 & 1 & 0.05 & 2 & 0.16 & 4 \\
\hline Voltage support & 0.01 & 1 & 0.26 & 12 & 0.89 & 21 \\
\hline System control & 0.16 & 10 & 0.15 & 7 & 0.14 & 3 \\
\hline Totals & 1.57 & 100 & 2.29 & 100 & 4.31 & 100 \\
\hline
\end{tabular}

${ }^{a}$ The numbers in parentheses are the average load and energy price for each segment of the load-duration curve. 


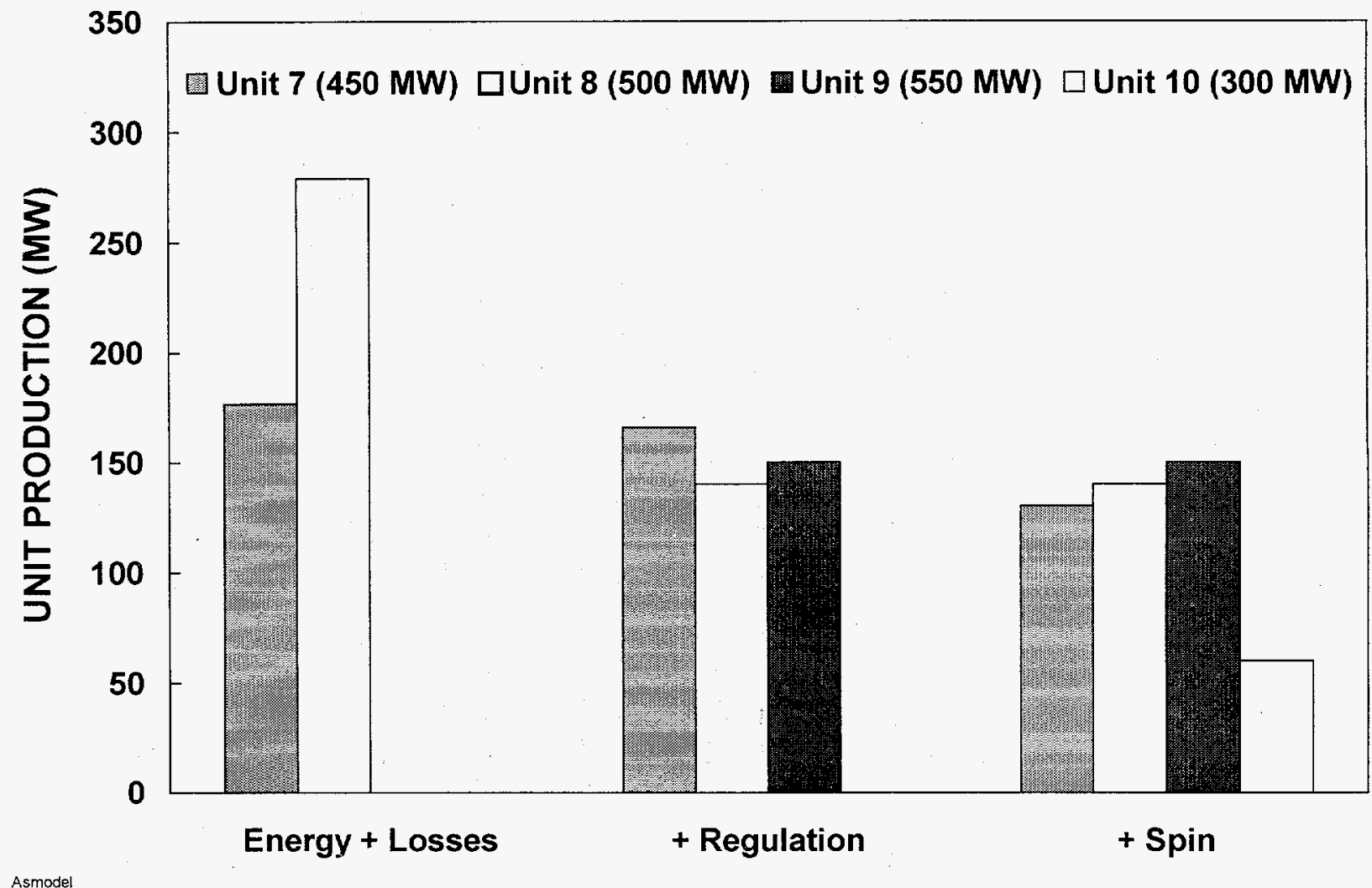

Fig. 12. The production from four generating units used to provide energy, losses, regulation, and spinning reserve when the system load is $5000 \mathrm{MW}$. The dispatch labeled Spin represents the actual operation of these units. (The numbers in parentheses in the key represent the unit's capability.)

As the "output" from these units is shifted back and forth to meet the various needs for energy and ancillary services, the system costs of these services (especially the opportunity cost) vary, which explains why many of the curves presented above have erratic patterns.

Figure 13 shows the implicit price of energy at the close of four markets: energy, energy-plus-losses, regulation, and spin. In practice, the prices at the close of the energy-plusloss market will likely determine the prices that customers pay and the earnings that generators receive for energy. Although all four price trajectories slope upward, they display the same kind of erratic behavior shown above. 


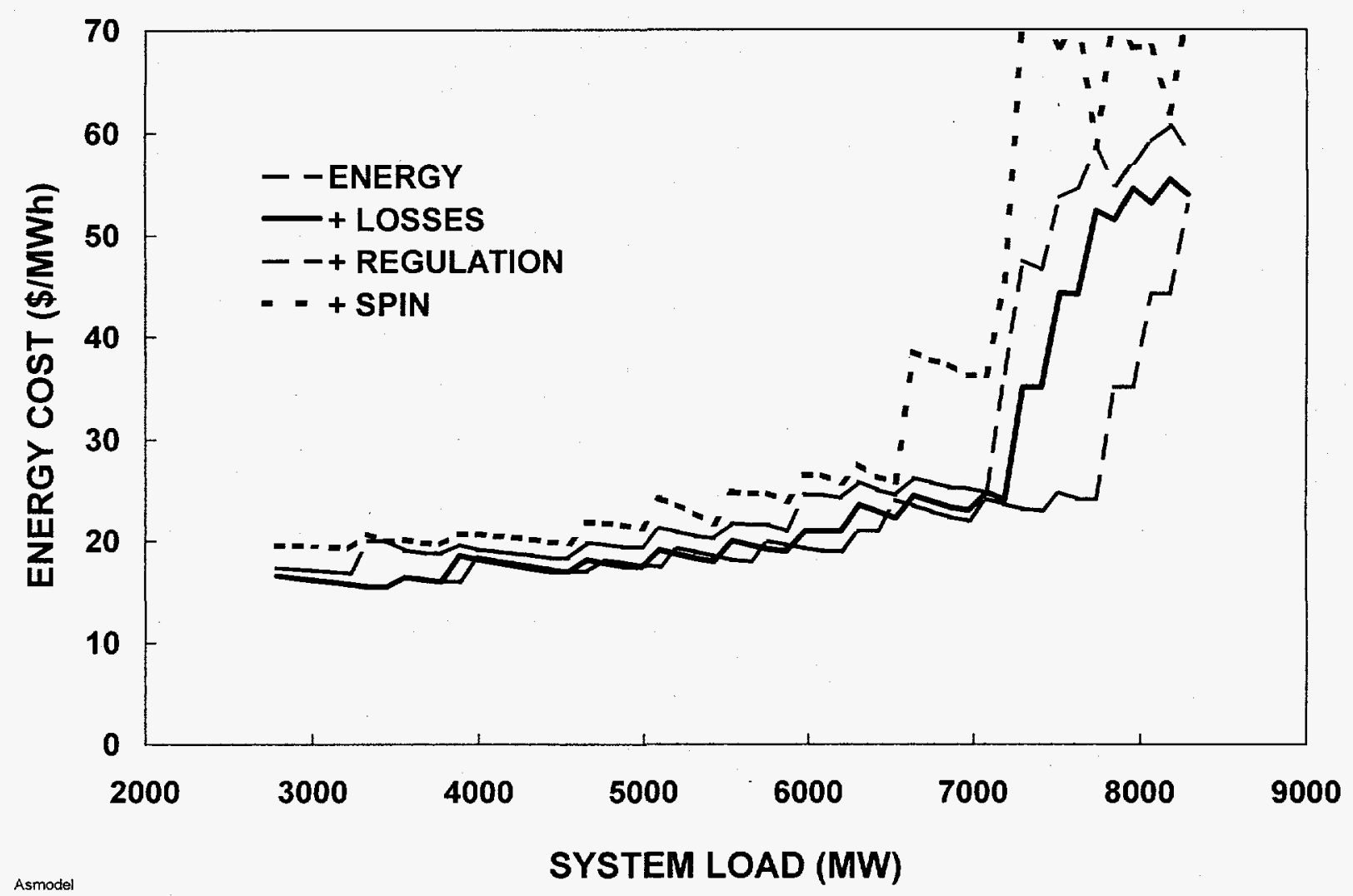

Fig. 13. Implicit spot prices for energy at the close of markets for energy, energy plus losses, energy plus losses plus regulation, and energy plus losses plus regulation plus spinning reserve.

Finally, Fig. 14 shows the share of total profits derived from the sale of ancillary services for the 17 units that operate when system load is at $6500 \mathrm{MW}$. The units are ordered from left to right in terms of increasing variable cost $(\$ / \mathrm{MWh})$. Those units operating at full output (baseload units) earn ancillary-service profits only from the sale of voltage support. Generators 10 through 13 earn additional profits from the sale of regulation and spinning reserve. (Unit 9 also provides spinning reserve but recovers only its costs for doing so.) Units 10 and 11 provide load following, but only Unit 11 earns money doing so. Units $14,19,20$, and 22 sell only supplemental reserve (i.e., they produce no energy at this load level). Units 15,17 , $18,21,23,24$, and 25 do not operate at all. At this load level, the share of earnings from ancillary services ranges from $6 \%$ to $100 \%$ across the 17 units in operation at that time. 


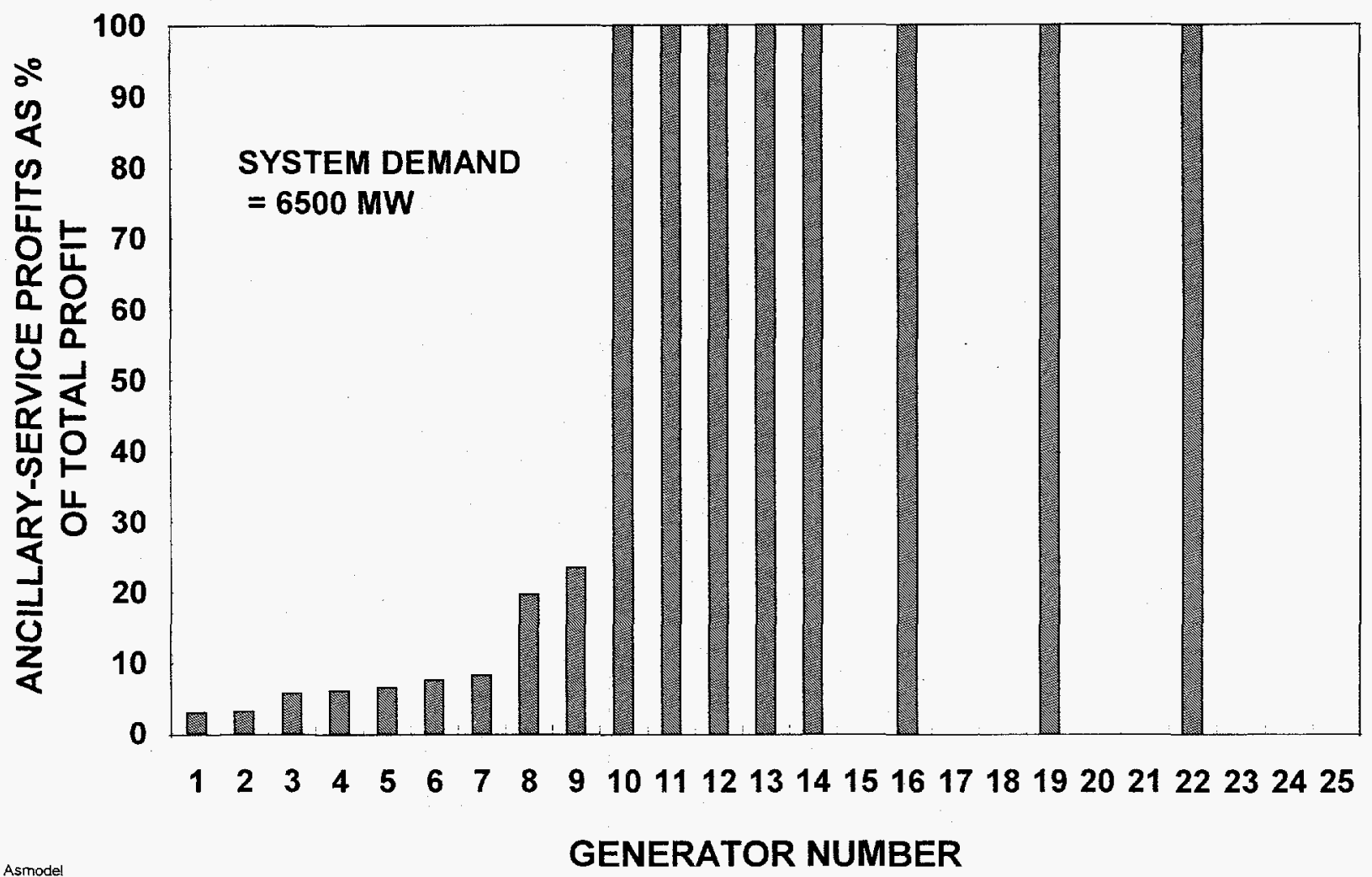

Fig. 14. The percentage of total profit from the sale of ancillary services for individual generators when the system load is $6500 \mathrm{MW}$. Units 10 and 11 set the price for energy plus losses. Units 10 through 13 generate profits through the sale of regulation and spin. Units 14, 16, 19, 20, and 22 provide supplemental reserve only; Unit 20 generates no earnings from its sale of this service because its bid sets the market price for supplemental reserve. 


\section{CONCLUSIONS}

The recent independent system operator filings with FERC propose to create markets in ancillary services. However, the definitions of these services are not always clear. Some filings have gaps, especially the omission of load following from all of them. Also, some overlaps occur, especially the inclusion within operating reserves of regulation and at least part of load following. Most of these filings, with California as the prime exception, are vague on the structure and operations of ancillary-service markets. They are very much works in progress with "design changes dictated on an almost daily basis" (Lock 1997).

This vagueness is unfortunate because these markets are highly interactive, not only with each other but also with the basic energy market. This interactiveness occurs because the same pieces of equipment (i.e., generating units) provide both the basic energy service and most of the ancillary services. In some cases, an ancillary service cannot be provided unless the unit is already online and providing energy (e.g., regulation and spinning reserve). In other cases, provision of an ancillary service limits the amount of capacity that can be sold into the energy market (again, regulation and spinning reserve). Speaking metaphorically, generators cannot be in two places [markets] at once! As Kirsch (1996) notes, ancillary-service prices will be closely related to the prices for generating capacity and energy. Indeed, the results presented above showed that, for the particular base case analyzed here, energy prices explain more than $90 \%$ of the variation in aggregate ancillary-service prices.

In addition, the prices and costs of these services will depend on how the markets are structured. For example, is the system operator seeking to minimize total system costs, or is it trying to minimize customer prices? Are markets cleared sequentially or simultaneously? Does the system operator manage the unit-commitment process across energy and the ancillary services, or do individual suppliers assume the risks of poor decisions and self-commit their units? In our model, the system operator makes many decisions as it opens and then clears each market to balance generation with load and to respect the constraints imposed on generators by the provision of certain ancillary services. These system-operator decisions, especially redispatch of operating units, can lead to situations in which the prices paid to the generators that provide a particular ancillary service are not equal to the prices that consumers pay for that service. But one can envision alternative ways to operate these markets; such alternatives would likely yield different outcomes in terms of consumer prices, producer profits, and even system operation and reliability.

Competitive markets should provide appropriate incentives to suppliers and consumers. To be efficient, such markets must also make available information to those who can act on that 
information. Much of this information can come only from the system operator (e.g., on the system requirements for regulation, operating reserves, and voltage schedules). On the other hand, only generators know their own cost structure. A key question is whether information and the associated decision making should be centralized in the hands of the system operator or decentralized and placed in the hands of individual market participants. A key consideration concerning dissemination of information is the need to prevent market-power problems (a topic not discussed here).

The model presented here and its results suggest several important findings concerning ancillary services:

- The embedded-cost prices used by most utilities in developing their FERC-required Order 888 pro forma tariffs bear little relationship to the likely operation of competitive markets. These tariffs set prices that ignore opportunity costs, overemphasize capital costs, and are generally invariant with time. In competitive markets, prices will be largely independent of capital and other unavoidable fixed costs, will depend strongly on opportunity costs, and will vary from hour to hour throughout the year.

- The energy and ancillary-services markets will be closely coupled. The prices of ancillary services will generally depend on current energy prices.

- For the base-case system analyzed here, aggregate ancillary-service prices amount to about $10 \%$ of direct energy prices. Losses are the most expensive of the ancillary services, accounting for about a third of the total ancillary-service bill. Load following, regulation, voltage support, and spinning reserve each account for 10 to $20 \%$ of the total. And scheduling, energy imbalance, and supplemental reserve each account for only a few percent of the total.

- Although ancillary-service prices increase with system load (and with spot energy prices), the profitability of selling these services varies erratically over time and system loads. For the case analyzed here, generators, on average, gain about $12 \%$ of their profits from ancillary services. The percentage of earnings from ancillary services increases with system load until loads reach about $80 \%$ of annual peak. Thereafter, ancillary-service earnings decline as a share of the total.

- The important issue is not the precise numbers concerning the profits and costs of ancillary services. The key issue is the variation over time (as functions of system load and energy price) in the costs and profitability of individual services. This variability suggests that the owners of generating units will need to pay close attention to temporal shifts in the prices of all these services as they decide how to bid into the various markets. 
To date, the developers of the various system-operator proposals have focused most of their time and attention on governance and transmission pricing. The model and results developed here suggest that attention should soon shift to more serious considerations of ancillary services.

\section{ACKNOWLEDGMENTS}

We thank Malcolm Bertsch, Stephen DeMarco, Michael Evans, William Hogan, Marija Ilic, Laurence Kirsch, Daniel Kirshner, John Malley, Steven Naumann, Steven Stoft, and Richard Tabors for their very helpful comments on a draft of this report. We thank Fred O'Hara for editing the report; and we thank Ethel Schorn for managing the clearance, publication, and distribution process. 



\section{REFERENCES}

Atlantic City Electric et al. 1997, Filing of the PJM Supporting Companies, Docket No. EC9738-000, before the Federal Energy Regulatory Commission, Norristown, PA, June 2.

M. L. Baughman, S. N. Siddiqi, and J. W. Zarnikau 1997, "Advanced Pricing in Electrical Systems Part I: Theory and Part II: Implications," IEEE Transactions on Power Systems 12(1), 489-502, February.

D. Curtice 1997, Cost of Providing Ancillary Services from Power Plants, Volume 1: A Primer, EPRI TR-107270-V1, Electric Power Research Institute, Palo Alto, CA, March.

E. Hirst 1997, Competition Can Enhance Bulk-Power Reliability, Electricity Consumers Resource Council, Washington, DC, June.

E. Hirst and B. Kirby 1996a, Electric-Power Ancillary Services, ORNL/CON-426, Oak Ridge National Laboratory, Oak Ridge, TN, February.

E. Hirst and B. Kirby 1996b, Ancillary-Service Details: Regulation, Load Following, and Generator Response, ORNL/CON-433, Oak Ridge National Laboratory, Oak Ridge, TN, September.

E. Hirst and B. Kirby 1997, Ancillary-Service Details: Operating Reserves, ORNL/CON-452, Oak Ridge National Laboratory, Oak Ridge, TN, November.

W. W. Hogan 1993, "Markets in Real Electric Networks Require Reactive Prices," The Energy Journal 14(3), 171-200.

M. D. Ilic, F. C. Graves, L. H. Fink, and A. M. DiCaprio 1996, "A Framework for Operations in the Competitive Open Access Environment," The Electricity Journal 9(3), 61-69, April.

Interconnected Operations Services Working Group 1997, Defining Interconnected Operations Services Under Open Access, EPRI TR-108097, Electric Power Research Institute, Palo Alto, CA, May.

B. Kirby and E. Hirst 1996, Ancillary-Service Costs for 12 U.S. Electric Utilities, ORNL/CON427, Oak Ridge National Laboratory, Oak Ridge, TN, March.

L. D. Kirsch 1996, Preparing the Ground for Pricing Unbundled Electricity Services: The Importance of Markets, EPRI TR-106933, Christensen Associates, prepared for the Electric Power Research Institute, Palo Alto, CA, November. 
L. D. Kirsch and H. Singh 1995, "Pricing Ancillary Electric Power Services," The Electricity Journal 8(8), 28-36, October.

R. Lock 1997, "Managing California's 'Big Middle': Options for Unbundling, Challenges for Regulation," The Electricity Journal 10(6), 28-37, July.

New England Power Pool 1996, New England Power Pool (NEPOOL) Restructured Arrangements (Including Open Access Transmission Tariff), before the Federal Energy Regulatory Commission, Holyoke, MA, December 31.

New York Power Pool 1997, Comprehensive Proposal to Restructure the New York Wholesale Electric Market, before the Federal Energy Regulatory Commission, Albany, NY, January 31.

S. S. Oren, A. J. Svoboda, and R. B. Johnson 1996, Equity and Efficiency of Unit Commitment in Competitive Electricity Markets, PWP-039, Program on Workable Energy Regulation, University of California, Berkeley, CA, June.

Pacific Gas and Electric, San Diego Gas \& Electric, and Southern California Edison 1997, The Phase II Filing of the California Independent System Operator Corporation and The Phase II Filing of the California Power Exchange Corporation, Docket Nos. EC96-19-001 and ER961663-001, before the Federal Energy Regulatory Commission, San Francisco, San Diego, and Rosemead, CA, March 31.

PJM Interconnection LLC 1997, "Historical Market Information, Market Clearing Price," $\mathrm{ftp}: / /$ www.pjm.com/pub/account/mcp.txt, accessed in August.

San Diego Gas \& Electric 1996, "Appendix E: Reserves Pricing," Explanatory Statement of San Diego Gas \& Electric Company, Docket Nos. EC96-19-000, ER96-1663-000, before the Federal Energy Regulatory Commission, San Diego, CA, June 28.

U.S. Federal Energy Regulatory Commission 1996, Promoting Wholesale Competition Through Open Access Non-Discriminatory Transmission Services by Public Utilities; Recovery of Stranded Costs by Public Utilities and Transmitting Utilities, Final Rule, Docket Nos. RM95-8000 and RM94-7-001, Order No. 888, Washington, DC, April 24.

U.S. Federal Energy Regulatory Commission 1997, Promoting Wholesale Competition Through Open Access Non-discriminatory Transmission Services by Public Utilities; Recovery of Stranded Costs by Public Utilities and Transmitting Utilities, Order on Rehearing, Docket Nos. RM95-8-001 and RM94-7-002, Order No. 888-A, Washington, DC, March 4.

A. J. Wood and B. F. Wollenberg 1996, Power Generation, Operation, and Control, $2^{\text {nd }}$ edition, John Wiley \& Sons, Inc., New York, NY. 


\section{INTERNAL DISTRIBUTION}

1. L. Baxter

2. V. D. Baxter

3. L. Berry

4. D. J. Bjornstad

5. M. A. Brown

6. J. Christian

7. G. Courville

8. T. R. Curlee

9. P. D. Fairchild

10. S. Hadley

11. L. J. Hill

12. E. Hirst

13. P. J. Hughes

14. B. Kirby

15. R. Lee
16. P. Leiby

17. J. M. MacDonald

18. V. C. Mei

19. D. E. Reichle

20. A. C. Schaffhauser

21. M. Schweitzer

22. R. B. Shelton

23. J. Tomlinson

24. B. E. Tonn

25. J. Van Dyke

26. J. VanCoevering

27. T. J. Wilbanks

28. Central Research Office

29. Document Reference Section

30. Laboratory Records (RC)

\section{EXTERNAL DISTRIBUTION}

31. Dr. Lilia A. Abron, President, PEER Consultants, P.C., 1000 N. Ashley Drive, Suite 312 , Tampa, FL 33602

32. Dr. Thomas E. Drabek, Professor, Department of Sociology, University of Denver, Denver, CO 80208-0209

33. Dr. Stephen G. Hildebrand, Director, Environmental Sciences Division, Oak Ridge National Laboratory, P.O. Box 2008, Oak Ridge, TN 37831-6037

34. Mr. P. Richard Rittelmann, FAIA, Executive Vice President, Burt Hill Kosar Rittlemann Associates, 400 Morgan Center, Butler, PA 16001-5977

35. Dr. Susan F. Tiemey, The Economic Resource Group, Inc., One Mifflin Place, Cambridge, MA 02138

36. Dr. C. Michael Walton, Ernest H. Cockrell Centennial Chair in Engineering and Chairman, Department of Civil Engineering, University of Texas at Austin, Austin, TX 78712-1076

37.-38. OSTI, U.S. Department of Energy, P.O. Box 62, Oak Ridge, TN 37831

39.

Office of Assistant Manager for Energy Research and Development, DOE/ORO, P.O. Box 2001, Oak Ridge, TN 37831-8600

40.-700 External Electric Industry Policy Studies group distribution mailing list and extra copies to E. M. Schorn, 4500N, H-19A 